\title{
Seismic performance investigation of new lateral bracing system called "OGrid-H"
}

\author{
Maryam Boostani ${ }^{1} \cdot$ Omid Rezaifar $^{2} \cdot$ Majid Gholhaki ${ }^{2}$
}

(c) Springer Nature Switzerland AG 2019

\begin{abstract}
This paper treats a different type of bracing by using circular bracing elements called OGrid-H. The goal of using circular shape is to obtain more ductility, high performance and appropriate stiffness and limit the buckling of braces, and at the same time in order to realize a solution that is interesting from the architectural point of view. In order to study the seismic behavior of OGrid-H members, a numerical finite element analysis of 9 OGrid-H models with different section members is established through ABAQUS finite element software subjected to cyclic loadings, which failure modes, load capacity, nonlinear displacement, ductility factor, vibration period, stiffness and energy absorption of models is obtained, and the comparison between outputs of models leads to obtaining the model with the best sections which have higher performance than the others. In order to investigate the OGrid-H connections, five changes are applied on connections, which the results showed that three changes had the greatest influence, which caused to increase load bearing as the amount of $22.88 \%$.
\end{abstract}

Keywords OGrid-H bracing system - Innovative lateral bracing system - Experimental behavior · Finite element analysis . Cyclic loading $\cdot$ Hysteresis curve $\cdot$ Steel structures

\section{Introduction}

Structures must have appropriate resistance to control the lateral displacements to restrain any structural and non-structural damage during the moderate but frequent earthquakes and also must have appropriate ductility and stability to restrain collapse under severe earthquakes. The capability of energy dissipation and having an appropriate stiffness is one of the most important specifications of a lateral load resisting system [1-4]. On the other hand, under a moderate earthquake, it is not economically justifiable to designing a structure which remains elastic [5-7]. So, in order to dissipate earthquake energy, the structure should experience inelastic behavior [8-15]. Extensive research has been performed to increase the ductility of concentric braces [16-31]. In addition, some studies have been performed on using circular elements in steel bracing systems in order to increase the ductility. Murty [32] used a circular element with hyperelastic material in a toggle bracing frame which this system showed an appropriate behavior under various levels of excitation, providing an excellent means of energy dissipation. Bazzaz et al. $[33,34]$ investigated the performance of off-centre bracing system with circular element (circular dissipater) under cyclic load which led to obtaining the best position of the ductile element and also this system showed good behavior with appropriate bending performance. Andalib et al. [35] performed an experimental study on the ductility and performance of the steel rings which

Omid Rezaifar, orezayfar@semnan.ac.ir; Maryam Boostani, maryamboostani@semnan.ac.ir; Majid Gholhaki, mgholhaki@semnan.ac.ir|'Faculty of Civil Engineering, Central Administration of Semnan University, Campus 1, Semnan 3513119111, Islamic Republic of Iran. ${ }^{2}$ Department of Civil Engineering, Central Administration of Semnan University, Campus 1, Semnan 3513119111, Islamic Republic of Iran. 
showed an appropriate behavior and high ductility and energy absorption. The performance of off-centre bracing system with circular element under monotonic load is performed by Bazzaz et al. [36]. Bazzaz et al. [37] also performed a numerical study in order to comparison of the seismic performance of off-centre bracing system with circular element and diagonal bracing system which showed that the off-centre bracing system with circular element has more ductility and absorption of energy compared to the diagonal bracing system model.

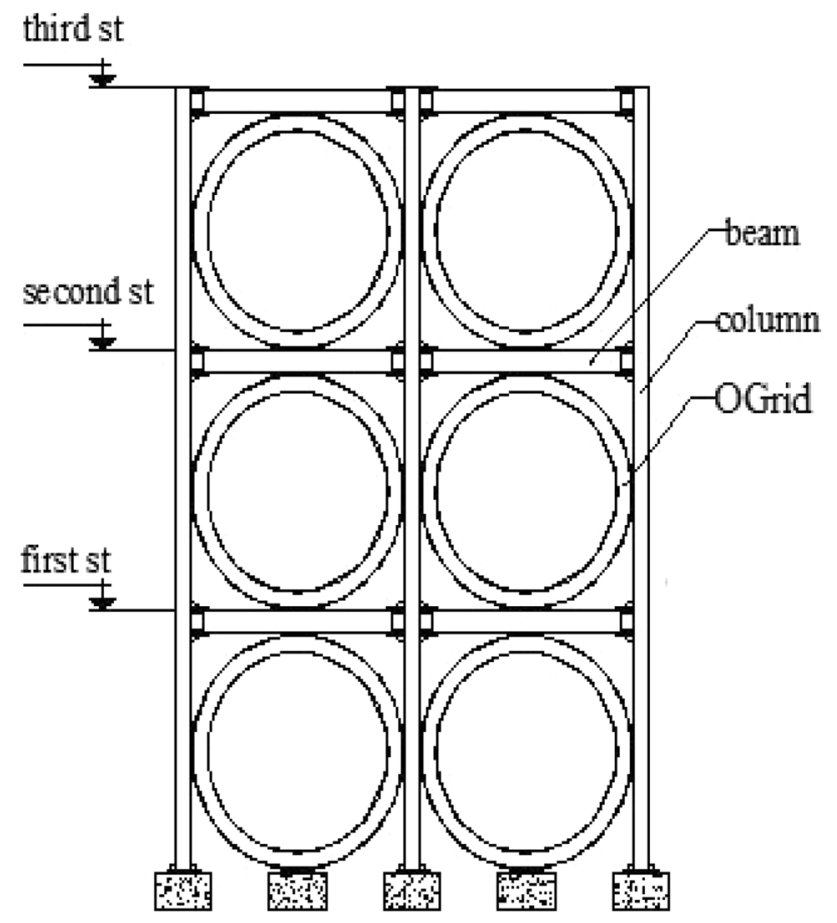

The latest investigation on using circular elements in steel bracing systems is conducted by Andalib et al. [38] on the ductility and energy dissipation capability of the steel rings constructed from two half-rings which shows the performance of steel rings made of two half-rings can be as effective as the ones made of a steel pipe.

The idea of the present research is also using the circular element in bracing systems but in a different way. One of the most important features of the structure's design is changing the form of structures to provide more stability and rigidity. So, the idea of using the circular shape for braces has been studied in this paper. In this new bracing system, increasing the load causes to change the geometry, so the specifications of this circular bracing system are geometrically nonlinear and lead to this circular bracing system has more ductility. This new bracing system, which has been called the OGrid, has been shown in Figs. 1, 2, 3 and 4 .

Previously, as a one-step of study on this new bracing system, an experimental study on the new OGrid bracing system and a numerical analysis in order to study on linear and nonlinear behavior of the OGrid bracing system in one story models have been performed by the authors [39]. To study the nonlinear behavior of OGrid-H bracing members; 9 single story and single-bay frame with brace OGrid-H have been analyzed and studied with ABAQUS FEA software. The Scope of this paper is research on the cyclic behavior of the OGrid-H bracing system with the different size of beam section, column section, and brace section, in order to investigate the influence of each changing on the behavior of the OGrid-H bracing system, and also research on the cyclic behavior of the OGrid-H bracing system with different connections.

Fig. 1 OGrid bracing system

Fig. 2 Schematic view of OGrid-H and OGrid-I bracing systems

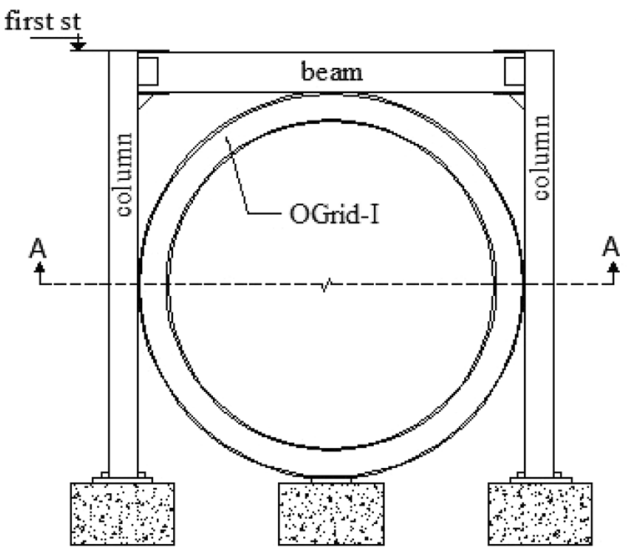

(a) OGrid-I bracing

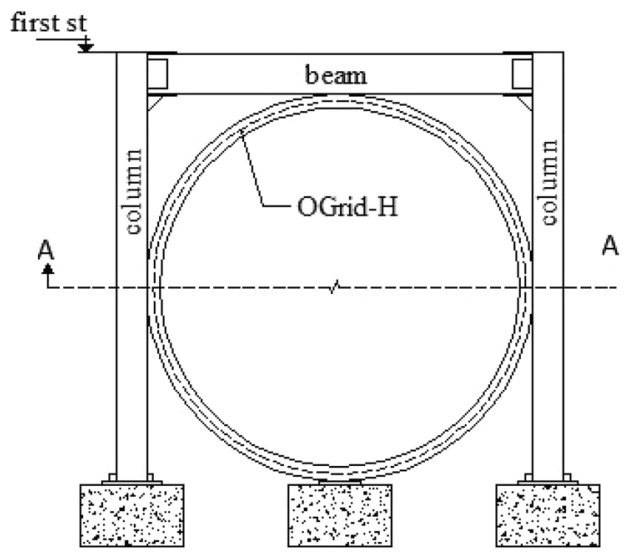

(b) OGrid-H bracing

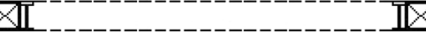

(d) OGrid-H bracing A-A section 
Fig. 3 The manufacturing processes of brace OGrid-H

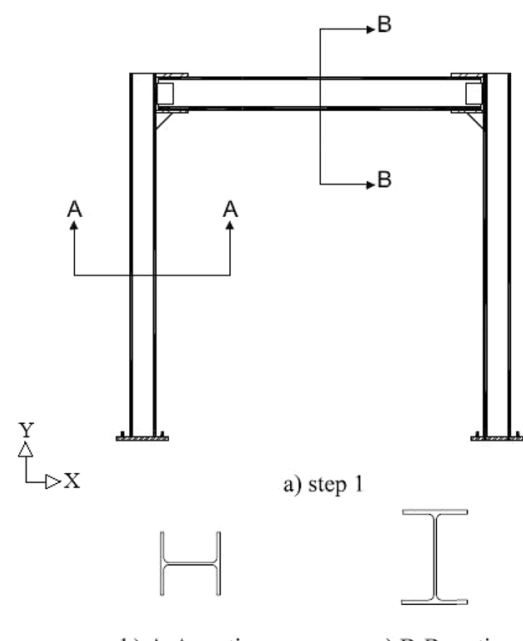

(a) Stage 1

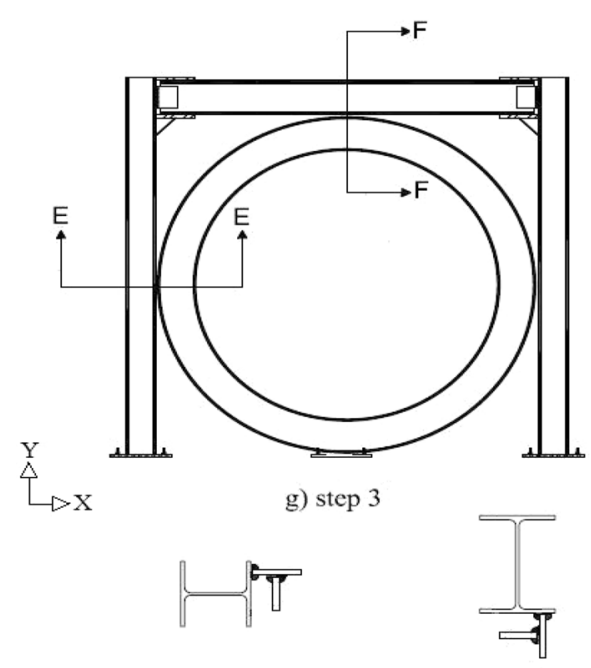

h) E-E section

(c) Stage 3

\section{New OGrid bracing system}

The OGrid bracing system is the circular bracing connected to moment resisting frame (MRF). Based on the used brace section, the OGrid bracing systems have been named OGrid-H and OGrid-I. The brace section in OGrid-H bracing system is $\mathrm{H}$-shaped, and in OGrid-I bracing system is I-shaped. Schematic view of OGrid-H and OGrid-I bracing systems is shown in Figs. 1 and 2.

The manufacturing processes of brace OGrid-H has been shown in Fig. 3. The first stage is to construct a frame using rigid connections, Fig. $3 \mathrm{a}$. In the second stage, in order to construct the brace OGrid- $\mathrm{H}$, steel

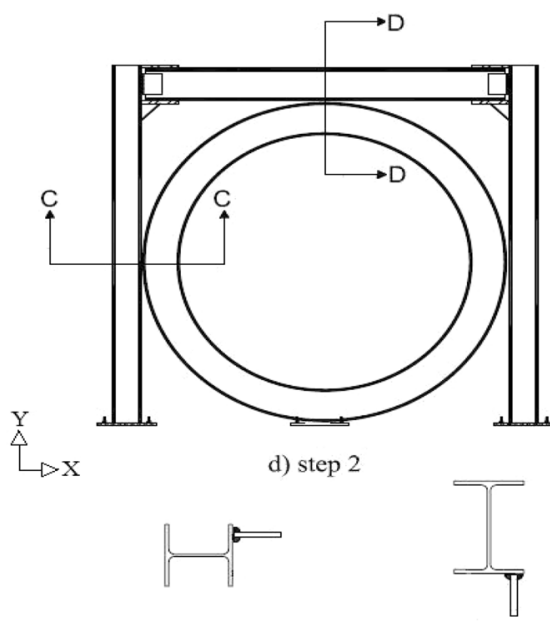

e) C-C section f) D-D section

(b) Stage 2

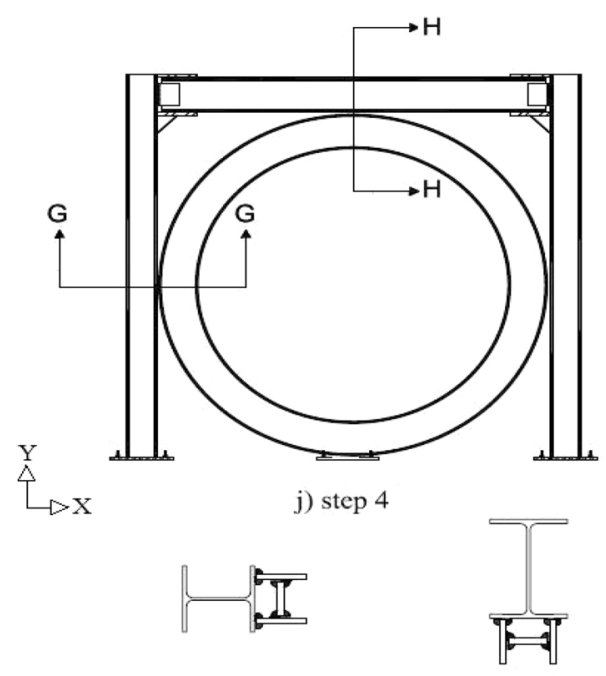

k) G-G section

1) $\mathrm{H}-\mathrm{H}$ section

(d) Stage 4

plate bent should rotate around the major axis and then it should weld to the beams and columns around. This makes the flange section, Fig. $3 \mathrm{~b}$. The third stage is to attach the web of bracing to the flange, Fig. $3 \mathrm{c}$. And the final stage, Fig. $3 d$, is to attach the steel plate to the web of bracing. Corner weld is used for welding of brace connections. For braces, hot-rolled sections can be applied. Also, instead of welding, the flange connection can be applied for prefabricated sections. Notably, the brace to frame connections should be rigid, due to the shape of the braces. Also, the manufacturing processes of brace OGrid-I has been shown in Fig. 4. 
Fig. 4 The manufacturing processes of brace OGrid-I

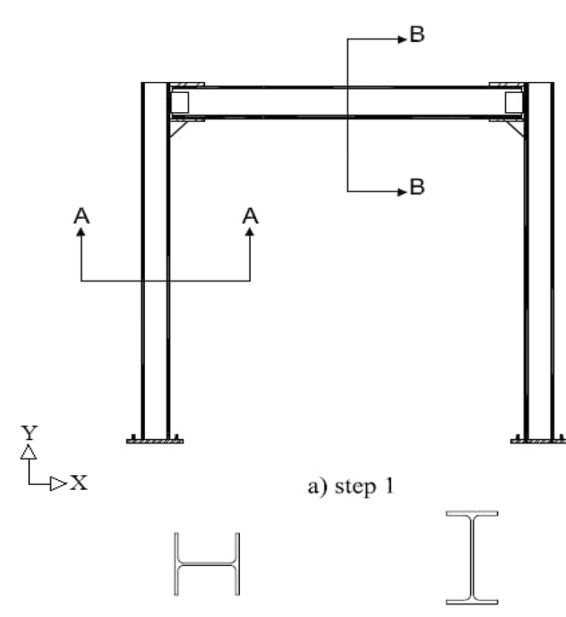

b) A-A section

c) B-B section

(a) Stage 1

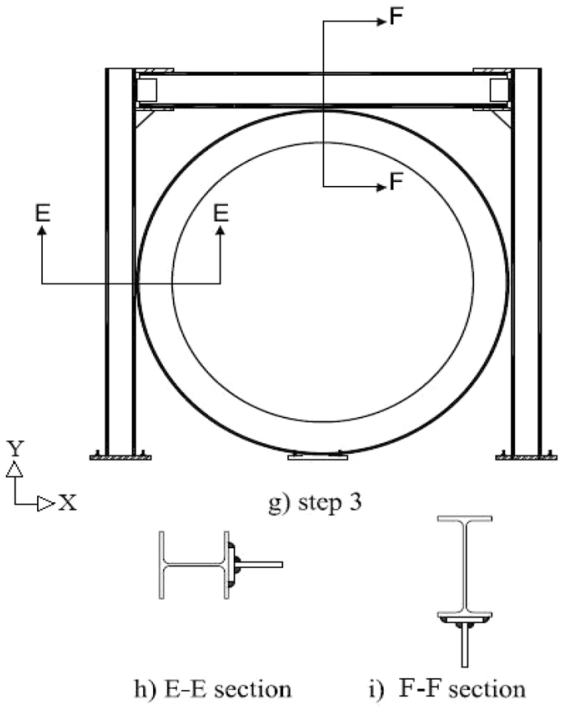

(c) Stage 3

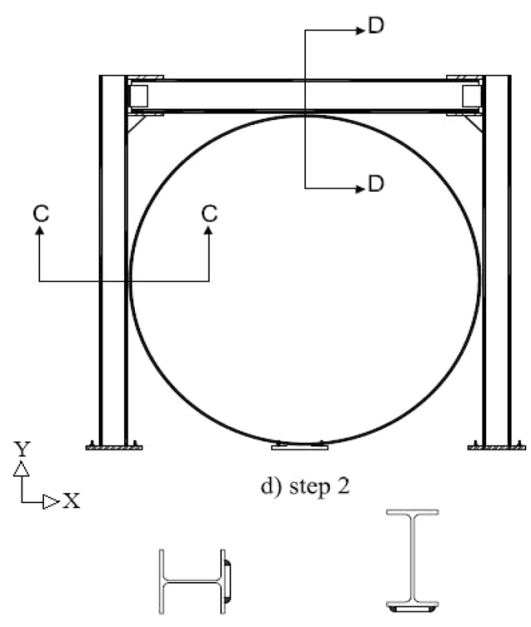

e) C-C section

(b) Stage 2

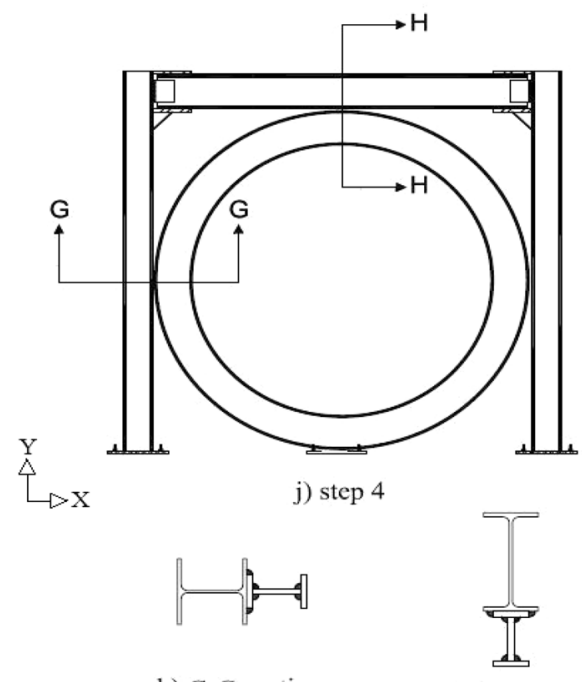

(d) Stage 4

\section{Analysis procedure}

\subsection{Modeling verification}

In order to validate the accuracy of the simulation, an experimental test conducted by the authors [39] has been used. The specimen was a one-bay and one-story steel frame reinforced with the OGrid-H bracing system. The tested specimen is presented in Fig. 5. Using the ABAQUS FEA software, the behavior of the OGrid-H specimen has been predicted analytically. According to material properties obtained from the experiment, bilinear steel properties has been employed. Cyclic loading protocol has been applied to the test specimens, and the displacement control method of ASTM E2126-07a standard [40] has been followed. A cubic three-dimensional 8-node element with reduced integration (C3D8R) has been adopted. In order to simulate the plastic deformations, a kinematic hardening rule with a Von Mises yielding criterion has been used. The Load-displacement result of the simulated OGrid-H bracing system under cyclic loading has been obtained. The model has been pushed until the peak strain reaches the ultimate strain. Figure 6 shows the comparison between load-displacement curves of the experimental and analytical models, which obtained by the backbone curve of the cyclic response. As shown in Fig. 6 the result of the simulation and the result of the experimental test are in good agreement. 


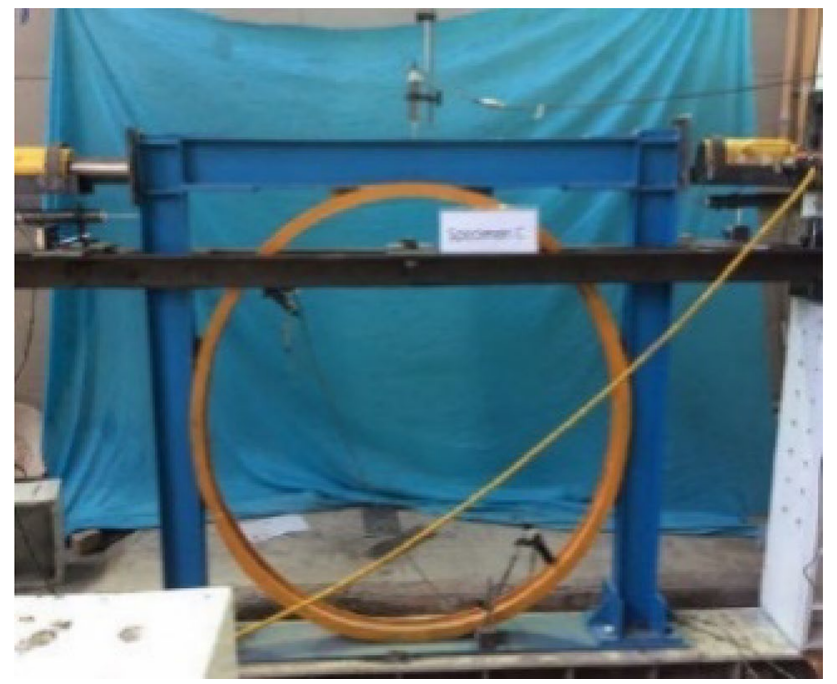

Fig. 5 Tested specimen [39]

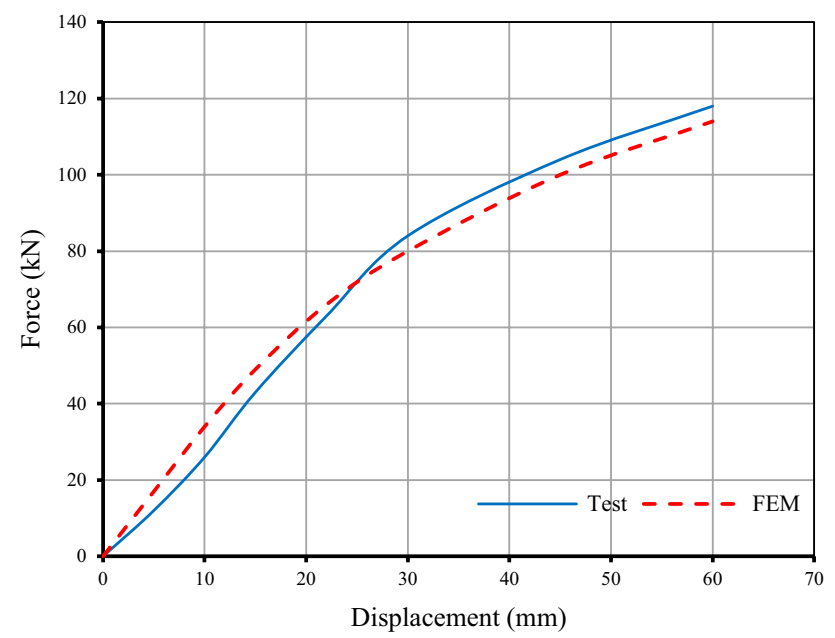

Fig. 6 Comparison between finite element modeling and test specimen result

\subsection{Selection of models configuration and design}

At first, a four-story moment resisting frame with the OGrid bracing system was modeled and analyzed with Etabs2015 software, Fig. 7a. The building was considered with office occupancy and was supposed to be located in Los Angeles. The structure loading was in accordance with ASCE 7-10 [41]. Loading (dead and live) for all stories were supposed to be $4 \times 10^{-6} \mathrm{kN} / \mathrm{mm}^{2}$ and $2.4 \times 10^{-6} \mathrm{kN} / \mathrm{mm}^{2}$, respectively. Based on the equivalent lateral force analysis, the seismic design was carried out. The special moment resisting frames (SMRF) type was considered for the frames. Calculation of the seismic response coefficient (Cs) has been presented in the following;

$S_{s}=2.1 \mathrm{~g}, S_{1}=0.93 \mathrm{~g}$, SiteClassD
$F_{a}=1.0, F_{v}=1.5$

$S_{M S}=F_{a} S_{s}=2.1 g, S_{M 1}=F_{v} S_{1}=1.4 g$

$S_{D S}=2 / 3 S_{M S}=1.4 g, S_{D 1}=2 / 3 S_{M 1}=0.93 g$

RiskCategory $=\| l I_{e}=1.00$

$R=8.0, \Omega_{0}=3.0, C_{d}=5.5$

$T_{0}=0.2 S_{D 1} / S_{D S}=0.13 s, T_{S}=S_{D 1} / S_{D S}=0.66 \mathrm{~s}$

$\mathrm{S}_{\mathrm{S}}=$ mapped maximum considered earthquake (MCE), spectral response acceleration at $0.2 \mathrm{~s}, \mathrm{~S}_{1}=$ mapped $\mathrm{MCE}$, spectral response acceleration at $1 \mathrm{~s}, \mathrm{~F}_{\mathrm{a}}=$ short-period site coefficient (at $0.2 \mathrm{~s}$-period), $\mathrm{F}_{\mathrm{v}}=$ long-period site coefficient (at $1 \mathrm{~s}$-period), $\mathrm{S}_{\mathrm{MS}}=$ the MCE spectral response acceleration (at $0.2 \mathrm{~s}$-period), $\mathrm{S}_{\mathrm{M} 1}=$ the MCE spectral response acceleration (at $1 \mathrm{~s}$-period), $\mathrm{S}_{D S}=$ the design basis earthquake (DBE), spectral response acceleration (at $0.2 \mathrm{~s}$-period), $\mathrm{S}_{\mathrm{D} 1}=\mathrm{DBE}$ spectral response acceleration (at $1 \mathrm{~s}$-period), $\mathrm{I}_{\mathrm{e}}=$ the importance factor, $\mathrm{R}=$ response modification coefficient, $\Omega_{0}=$ over-strength factor, $C_{d}=$ deflection amplification factor.

For the values of seismic response coefficient (Cs), 0.114 has been obtained and the design of the frame models was in accordance with AISC 360-10 code [42]. Eventually, for the frame extracted from the typical four-story OGrid$\mathrm{H}$ bracing frame, which has been shown in Fig. $7 \mathrm{~b}$, the beam section, column section, and brace section has been obtained IPE 300, H400 ×237, and IPE 140, respectively.

To evaluate the nonlinear behavior of OGrid-H bracing members; 9 single-story and single-bay steel hinged frames reinforced by brace OGrid-H have been analyzed and studied with ABAQUS FEA software. The goal of the research is to use circular brace optimally and investigate the influence of changing the beam section, column section and brace section on cyclic behavior of the OGrid-H bracing system. The first OGrid-H model has been selected as a one-story, one-bay frame extracted from a typical four-story OGrid-H bracing frame, shown in Fig. 7b, and the other 8 models have been selected through changing the brace section or the beam section or the column section, in order to investigate the influence of each changing on the behavior of the OGrid-H bracing system. In other words, the purpose of these changing to define the studied models was not for enough structural response and minimum sections for structural adequately, but also was for the maximum efficiency of the total system including beam, columns, and brace to extract their effective and useful stiffness ratios. Table 1 shows the section specification of the models and Table 2 shows the details of the sections. For better result description, models have been called with abbreviation names as shown in Table 1 . 


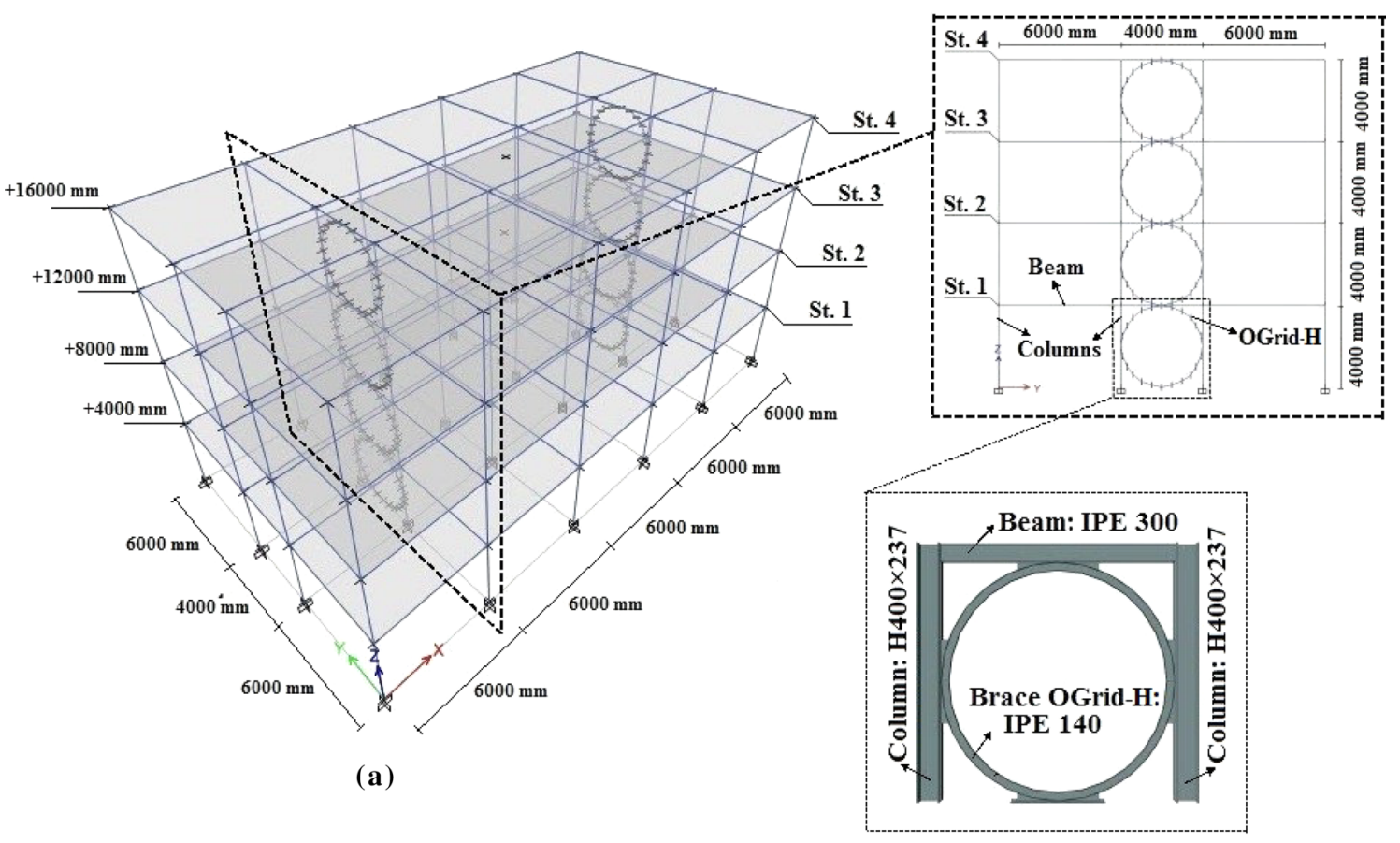

(b)

Fig. 7 Four-story structure for design of OGrid-H bracing system

Table 1 Models nomination and sections specification of 9 OGrid-H models

\begin{tabular}{|c|c|c|c|c|c|c|}
\hline $\begin{array}{l}\text { Abbreviation name of } \\
\text { models }\end{array}$ & Beam section & Beam type & Column section & Column type & Brace section & Brace type \\
\hline $\mathrm{OGH}-\mathrm{B} 1-\mathrm{C} 1-\mathrm{R} 1$ & IPE300 & B1 & $\mathrm{H} 400 \times 237$ & $\mathrm{C} 1$ & IPE140 & $\mathrm{R} 1$ \\
\hline $\mathrm{OGH}-\mathrm{B} 1-\mathrm{C} 1-\mathrm{R} 2$ & IPE300 & B1 & $\mathrm{H} 400 \times 237$ & $\mathrm{C} 1$ & IPE200 & $\mathrm{R} 2$ \\
\hline $\mathrm{OGH}-\mathrm{B} 1-\mathrm{C} 1-\mathrm{R} 3$ & IPE300 & B1 & $\mathrm{H} 400 \times 237$ & $\mathrm{C} 1$ & IPE270 & R3 \\
\hline $\mathrm{OGH}-\mathrm{B} 2-\mathrm{C} 1-\mathrm{R} 1$ & IPE400 & B2 & $\mathrm{H} 400 \times 237$ & $\mathrm{C} 1$ & IPE140 & $\mathrm{R} 1$ \\
\hline $\mathrm{OGH}-\mathrm{B} 2-\mathrm{C} 1-\mathrm{R} 2$ & IPE400 & B2 & $\mathrm{H} 400 \times 237$ & $\mathrm{C} 1$ & IPE200 & $\mathrm{R} 2$ \\
\hline $\mathrm{OGH}-\mathrm{B} 2-\mathrm{C} 1-\mathrm{R} 3$ & IPE400 & B2 & $\mathrm{H} 400 \times 237$ & $\mathrm{C} 1$ & IPE270 & R3 \\
\hline $\mathrm{OGH}-\mathrm{B} 2-\mathrm{C} 2-\mathrm{R} 1$ & IPE400 & B2 & $\mathrm{H} 400 \times 347$ & $\mathrm{C} 2$ & IPE140 & $\mathrm{R} 1$ \\
\hline $\mathrm{OGH}-\mathrm{B} 2-\mathrm{C} 2-\mathrm{R} 2$ & IPE400 & B2 & $\mathrm{H} 400 \times 347$ & $\mathrm{C} 2$ & IPE200 & $\mathrm{R} 2$ \\
\hline $\mathrm{OGH}-\mathrm{B} 2-\mathrm{C} 2-\mathrm{R} 3$ & IPE400 & B2 & $\mathrm{H} 400 \times 347$ & $\mathrm{C} 2$ & IPE270 & R3 \\
\hline
\end{tabular}

Table 2 Details of the sections

\begin{tabular}{llllllll}
\hline Section & IPE140 & IPE200 & IPE270 & IPE300 & IPE400 & H400×237 & H400×347 \\
\hline A $\left(\mathrm{mm}^{2}\right)$ & 1640 & 2850 & 4590 & 5380 & 8450 & 30,200 & 44,100 \\
$\mathrm{I}_{x}\left(\mathrm{~mm}^{4}\right)$ & $5,410,000$ & $19,430,000$ & $57,900,000$ & $83,560,000$ & $231,300,000$ & $797,100,000$ & $1,246,000,000$ \\
$\mathrm{I}_{y}\left(\mathrm{~mm}^{4}\right)$ & 449,000 & $1,420,000$ & $4,200,000$ & $6,040,000$ & $13,180,000$ & $313,500,000$ & $478,700,000$ \\
$\mathrm{r}_{x}(\mathrm{~mm})$ & 57.4 & 82.6 & 112.3 & 124.6 & 165.4 & 162.5 & 168.1 \\
$\mathrm{r}_{y}(\mathrm{~mm})$ & 16.5 & 22.3 & 30.2 & 33.5 & 39.5 & 101.9 & 104.2 \\
\hline
\end{tabular}

A, Cross section; $I_{x^{\prime}}$ Moment of inertia relative to the axis $x ; I_{y^{\prime}}$ Moment of inertia relative to the axis $y ; r_{x^{\prime}}$ The radius of gyration relative to the axis $x ; r_{y^{\prime}}$ The radius of gyration relative to the axis $y$ 
Models nomination is based on the types of beam, column, and brace that used in models. Sections are inclusive two beam types, two column types, and three brace types. In models nomination, OGrid-H models for simplification have been called $\mathrm{OGH}$, and then the types of beam, column, and brace have been expressed respectively, for example, OGH-B1-C1-R1.

\subsection{Finite element modeling}

The finite element analysis package, ABAQUS has been used to investigate the hysteresis behavior of OGrid bracing system. 9 single-story and single-bay steel hinged frames with brace OGrid-H have been analyzed and studied with ABAQUS FEA software subjected to cyclic loading. The present study aims to investigate the influence of changing the beam section, column section and brace section on the cyclic behavior of the OGrid-H bracing system and to achieve the maximum efficiency of the total system including beam, columns, and brace to extract their effective and useful stiffness ratios. The brace-to-frame connections have been shown in Fig. 8. As seen in Fig. 8, in OGrid$\mathrm{H}$ bracing system, one plate is located along the web of brace for brace-to-frame connections. Table 3 shows the details of the connection plates.

Steel was modeled as elastic-plastic hardening material using the classical metal plasticity model and tri-linear stress-strain relationship was used to predict the behavior of structural steel. For simulating the steel properties, the material properties for ST37 steel have been employed as follows: Young's modulus $E=210 \mathrm{kN} / \mathrm{mm}^{2}$, yield stress $f_{y}=0.24 \mathrm{kN} / \mathrm{mm}^{2}$, ultimate stress $f_{u}=0.37 \mathrm{kN} / \mathrm{mm}^{2}$, and Poisson's ratio $v=0.3$. Figure 9 presents the ST37 steel stress-strain diagram defined in the software. The density for all steel elements was taken to be $7.85 \times 10^{-8} \mathrm{kN} / \mathrm{mm}^{3}$. Three-dimensional
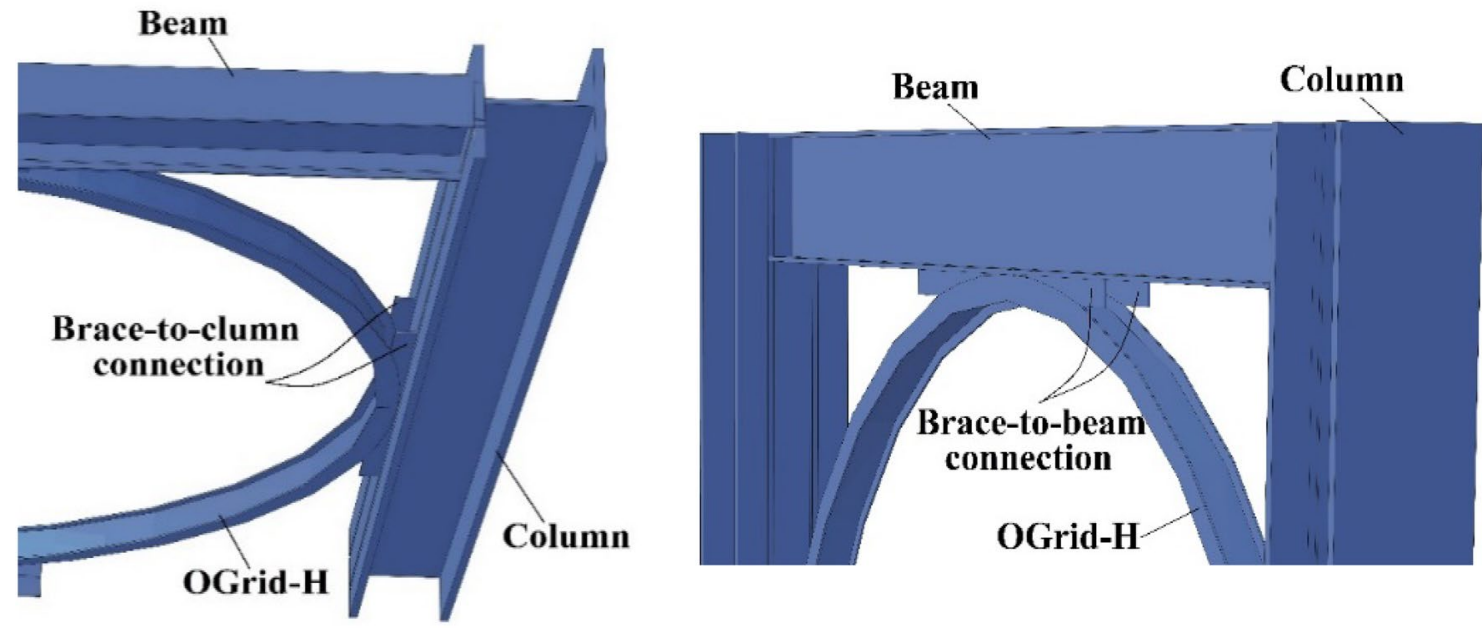

Fig. 8 Brace-to-frame connections of OGH

Table 3 Details of the connection plates

\begin{tabular}{|c|c|c|c|c|c|c|c|c|c|}
\hline Models & $\begin{array}{l}\text { OGH-B1- } \\
\text { C1-R1 }\end{array}$ & $\begin{array}{l}\mathrm{OGH}-\mathrm{B} 1- \\
\mathrm{C} 1-\mathrm{R} 2\end{array}$ & $\begin{array}{l}\mathrm{OGH}-\mathrm{B} 1- \\
\mathrm{C} 1-\mathrm{R} 3\end{array}$ & $\begin{array}{l}\mathrm{OGH}-\mathrm{B} 2- \\
\mathrm{C} 1-\mathrm{R} 1\end{array}$ & $\begin{array}{l}\mathrm{OGH}-\mathrm{B} 2- \\
\mathrm{C} 1-\mathrm{R} 2\end{array}$ & $\begin{array}{l}\mathrm{OGH}-\mathrm{B} 2- \\
\mathrm{C} 1-\mathrm{R} 3\end{array}$ & $\begin{array}{l}\mathrm{OGH}-\mathrm{B} 2- \\
\mathrm{C} 2-\mathrm{R} 1\end{array}$ & $\begin{array}{l}\mathrm{OGH}-\mathrm{B} 2- \\
\mathrm{C} 2-\mathrm{R} 2\end{array}$ & $\begin{array}{l}\text { OGH-B2- } \\
\text { C2-R3 }\end{array}$ \\
\hline $\begin{array}{l}\text { Connection } \\
\text { plates } \\
\text { length } \\
(\mathrm{mm})\end{array}$ & 1400 & 1400 & 1400 & 1400 & 1400 & 1400 & 1400 & 1400 & 1400 \\
\hline $\begin{array}{l}\text { Connection } \\
\text { plates } \\
\text { width } \\
(\mathrm{mm})\end{array}$ & 140 & 200 & 270 & 140 & 200 & 270 & 140 & 200 & 270 \\
\hline $\begin{array}{l}\text { Connection } \\
\text { plates } \\
\text { thickness } \\
(\mathrm{mm})\end{array}$ & 4.7 & 5.6 & 6.6 & 4.7 & 5.6 & 6.6 & 4.7 & 5.6 & 6.6 \\
\hline
\end{tabular}




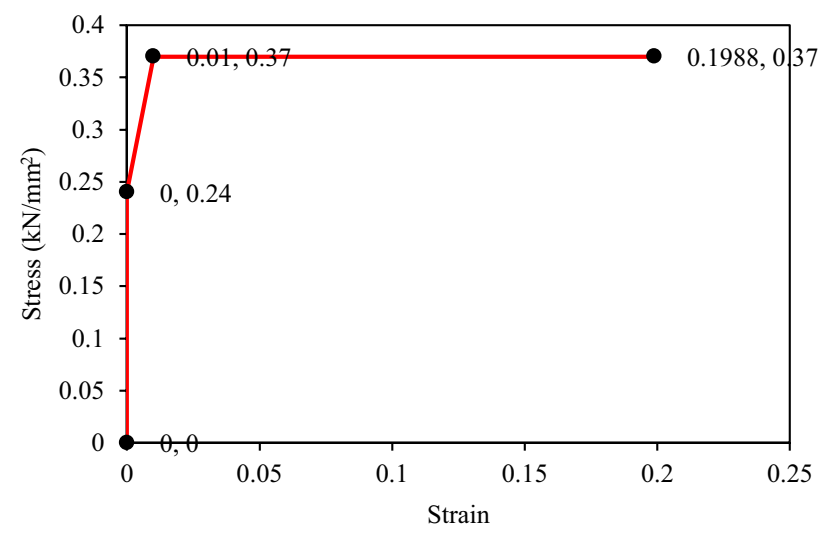

Fig. 9 ST37 steel stress-strain diagram defined in the software

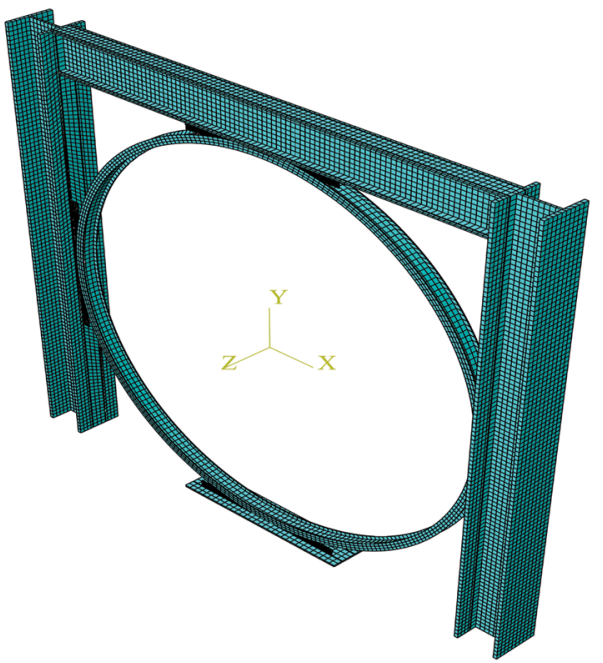

Fig. 10 View of the finite element mesh of the models

8-node solid element (element C3D8R in ABAQUS) with 3 degrees of freedom at each node to achieve a uniform stress distribution has been adopted in the analysis for all components of the models such as the beam; column, brace, connection plate and base plate. With an adequately fine mesh, these elements are capable of providing accurate solutions even in complex structures. The frame, the brace OGrid and connection plates have been merged together, and simulation of the weld has been neglected in the current study assuming that failure does not occur in the welds. The fixed boundary condition has been applied to the columns bases and the base plate of the brace while an axial force has been applied to the top of the column to investigate the behavior of the model. A mesh size of $40 \mathrm{~mm}$ has been utilized in the finite element simulation. Figure 10 shows a typical finite element meshing used in this study.

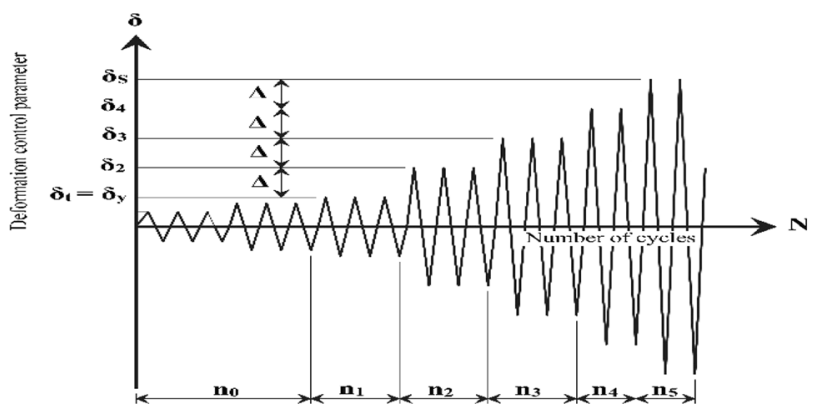

Fig. 11 Cyclic loading protocol in ATC-24 code [43]

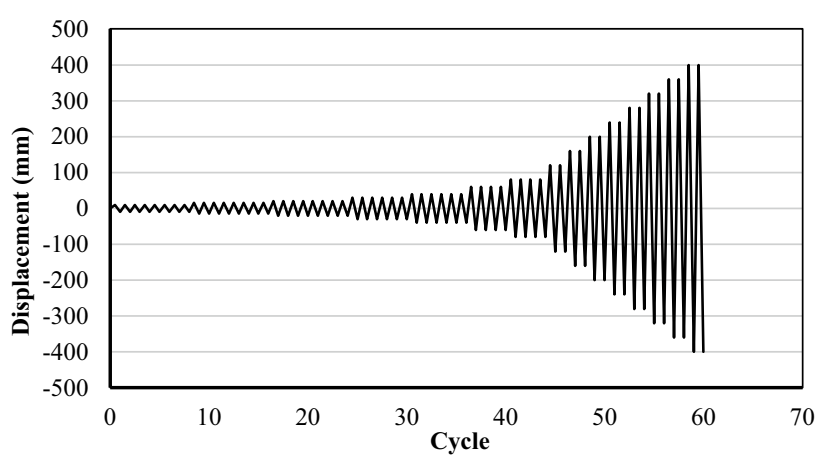

Fig. 12 Cyclic loading protocol of models in this paper

\subsection{Cyclic loading}

For models loading, displacement-control criterion has been used. The analysis has been performed by applying cyclic displacement at the top of the column. Since reciprocating the applied displacement, this loading type is so similar to earthquakes loads. Method of cyclic displacement amplitude is in accordance with the proposed cyclic displacement methods of ATC-24 code [43]. Loading protocol of ATC-24 code [43] has been presented in Fig. 11 , which in this figure, $\delta_{i}$ is the peak deformation in load step $\mathrm{i}, n_{i}$ is the number of cycles to be performed in load step $\mathrm{i}$, and $\Delta$ is the increment in peak deformation between two consecutive steps. Considering ATC24 code [43], loading protocol of models has been presented in Fig. 12. To specify the yield displacement of models (the displacement expected to yield the models), before the cyclic loading, a nonlinear analysis under monotonic loading was performed using ABAQUS FEA software. So $400 \mathrm{~mm}$ maximum displacement for cyclic loading protocol of all models has been selected, which is more than the required displacement for yielding of each model.

\section{SN Applied Sciences}




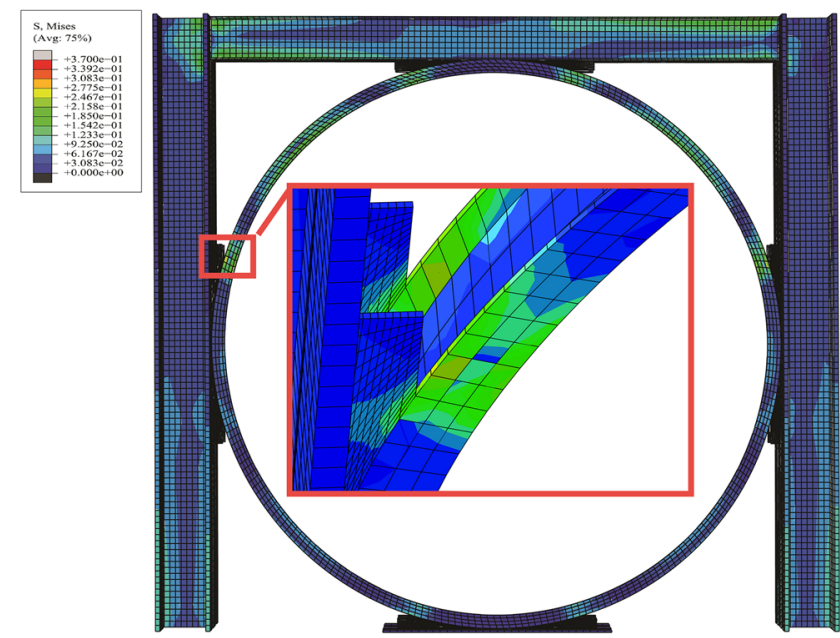

(a)

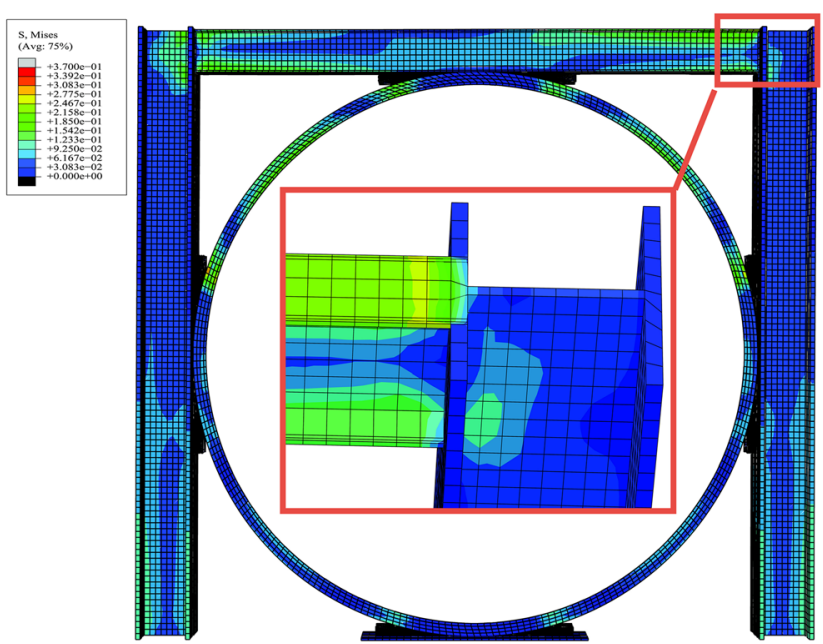

(c)

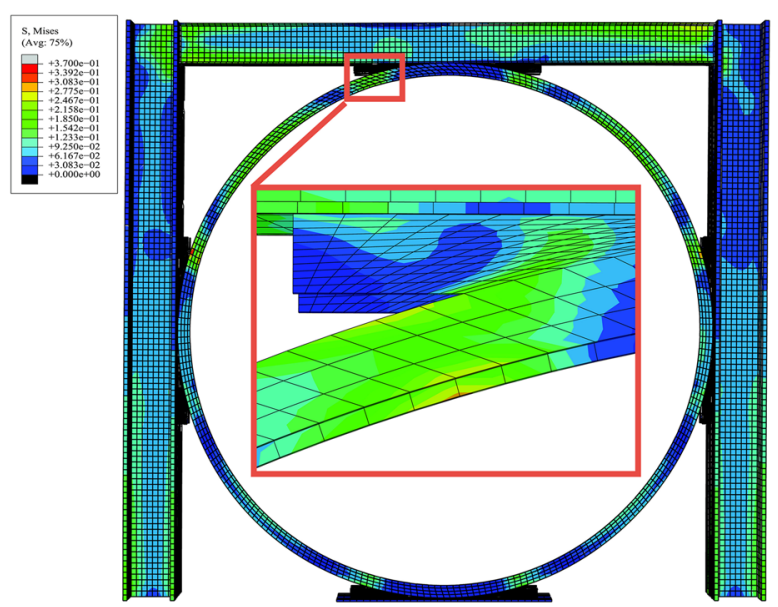

(e)

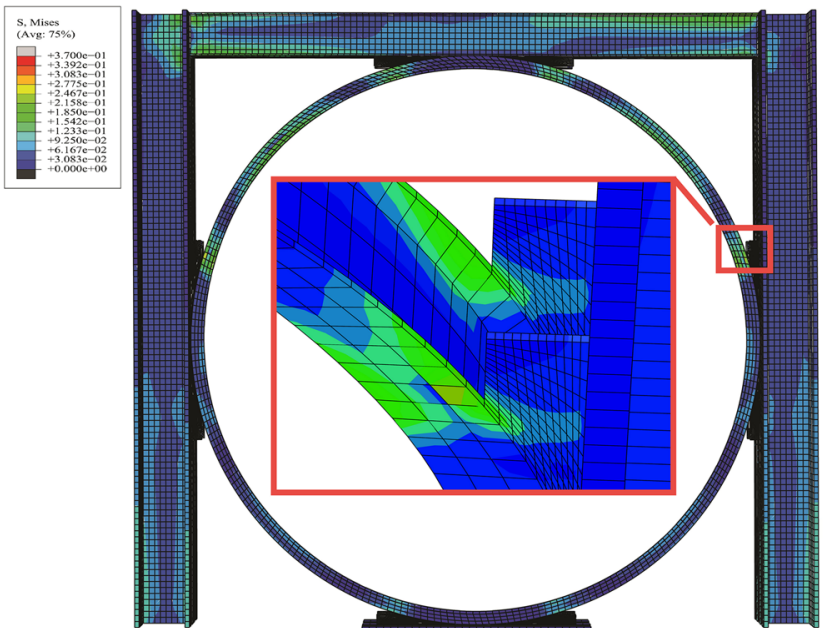

(b)

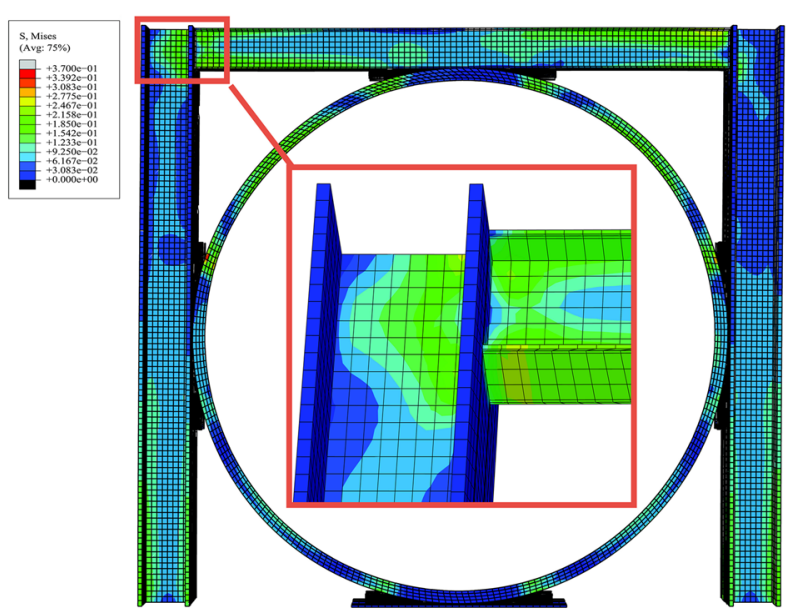

(d)

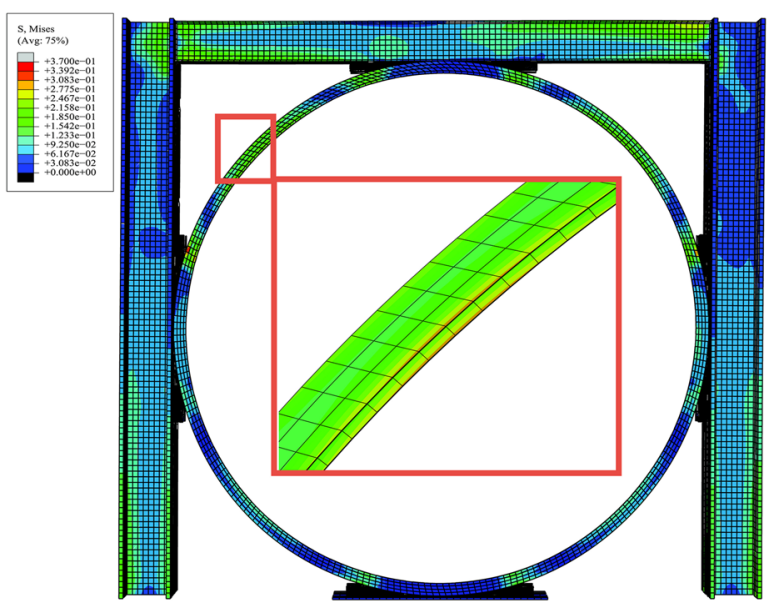

(f)

Fig. 13 Initial yielding in OGrid-H bracing system 


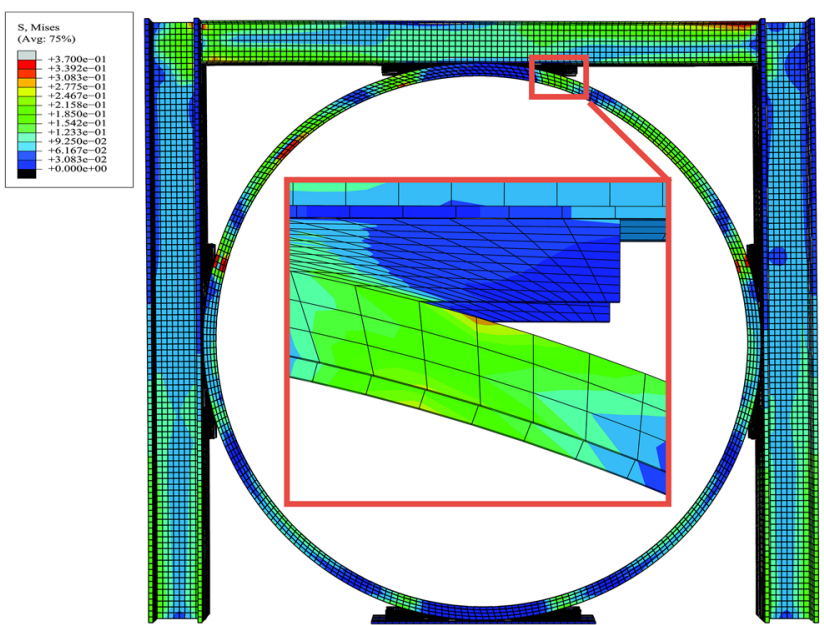

(g)

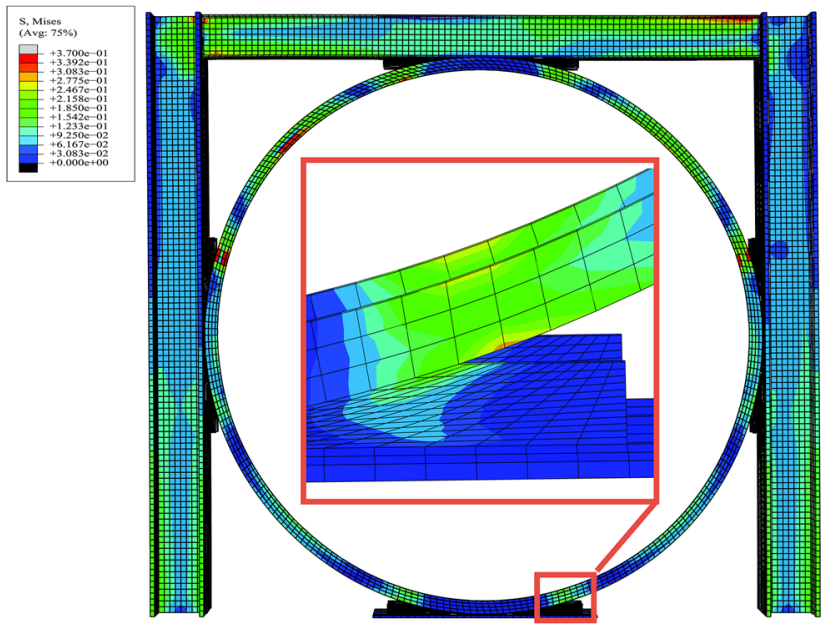

(i)

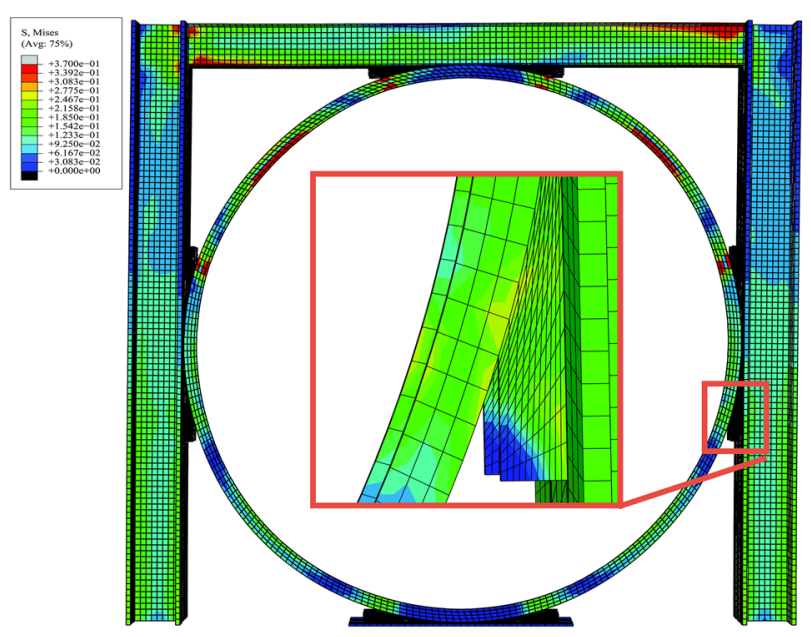

(k)

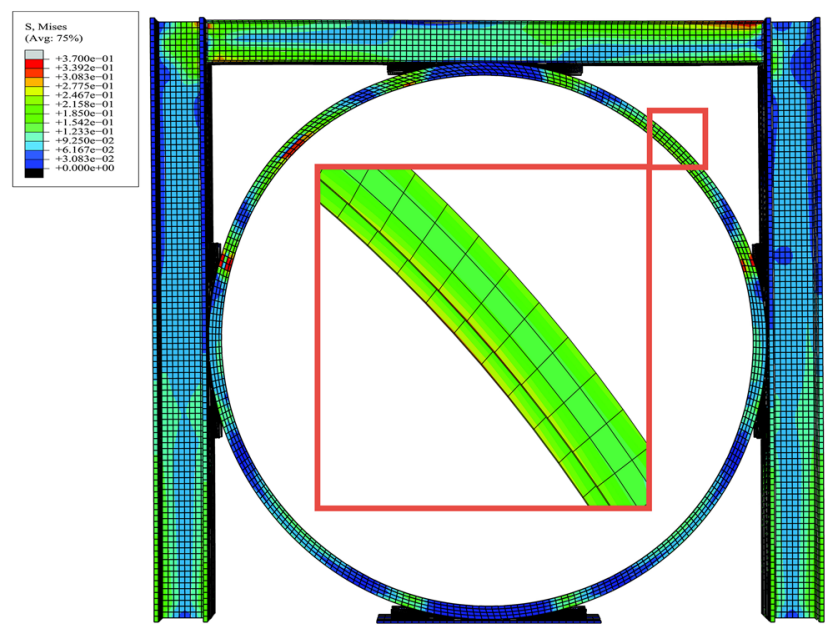

(h)

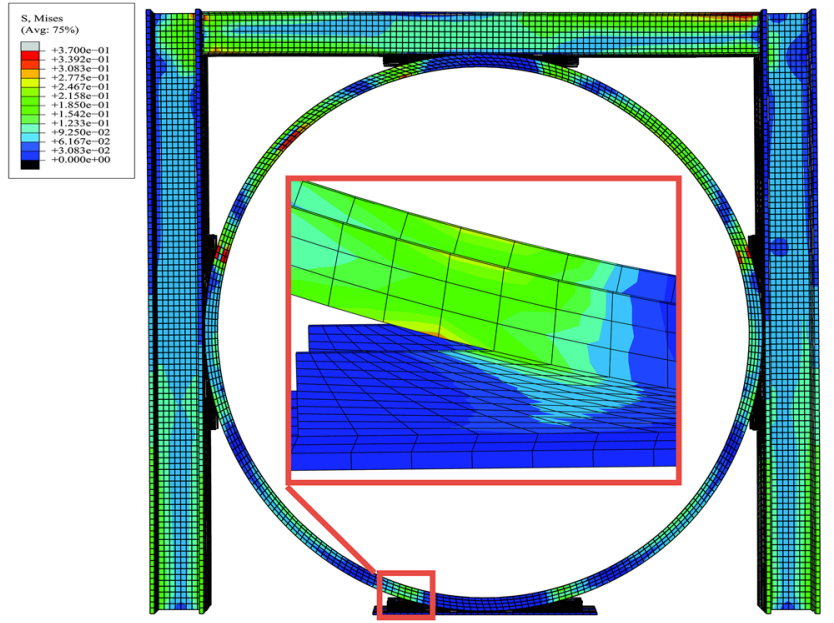

(j)

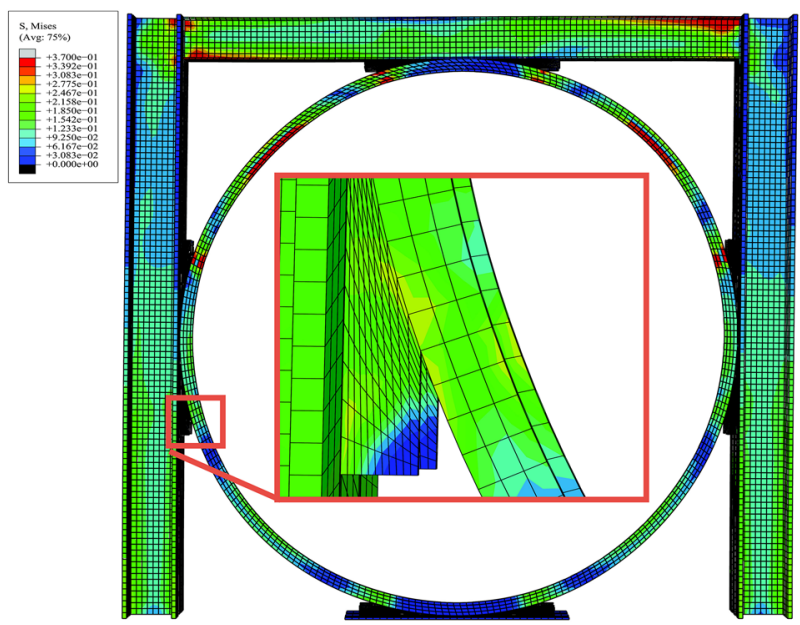

(I)

Fig. 13 (continued) 


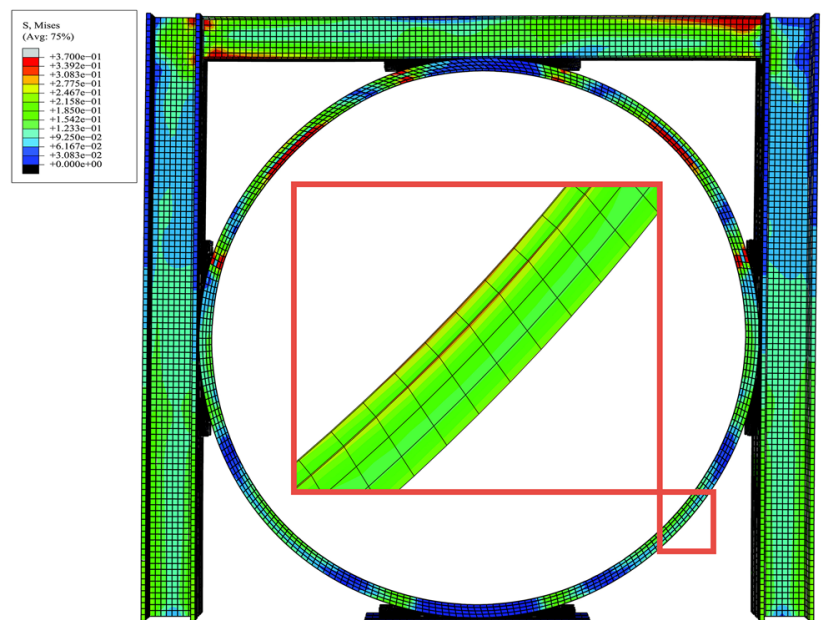

(m)

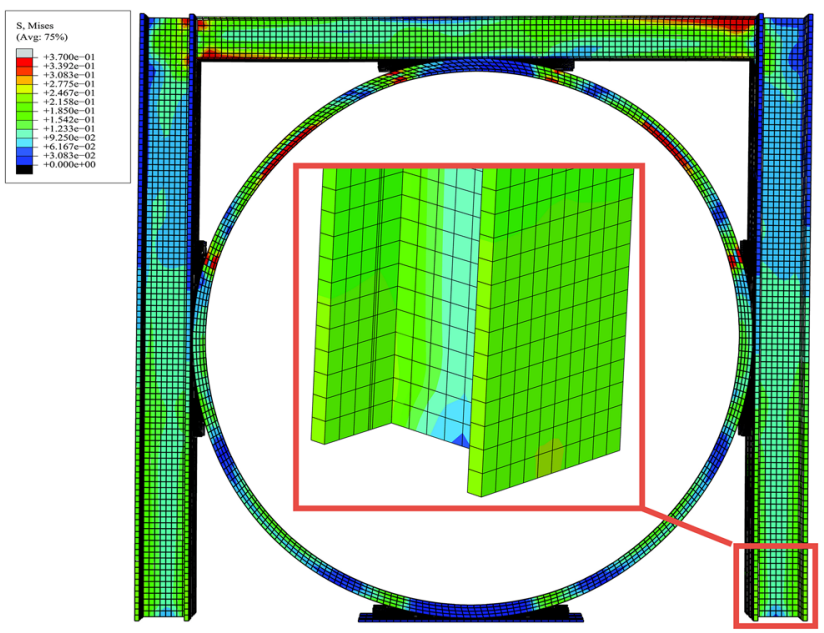

(o)

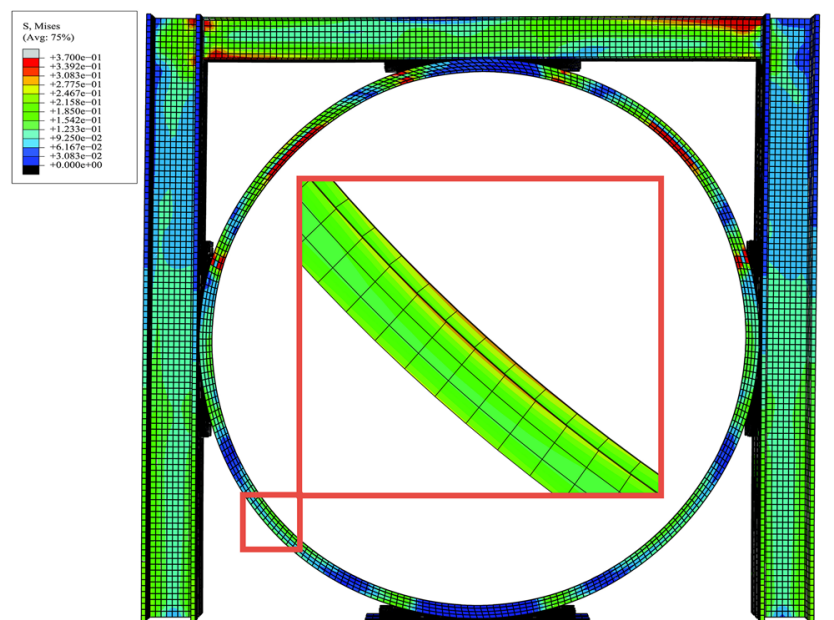

(n)

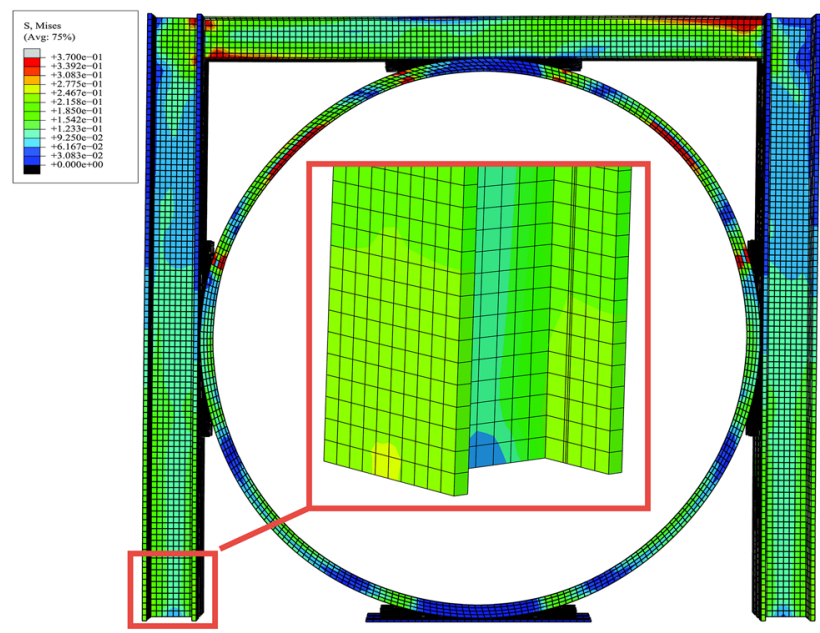

(p)

Fig. 13 (continued)

\section{Results}

\subsection{Failure modes of models}

Formation and number of plastic hinges show the behavior of structure against lateral loads. Whatever many plastic hinges formed in more members, indicates much nonlinearity capacity of structure and more members are involved in absorbing the earthquake energy.

Failure modes of OGH-B1-C1-R1 have been described as follows. Initial yielding happened during the eighth cycle, with yielding observed at the flange of the brace in brace-to-column connection, Fig. 13a. It should be noted that during that cycle, other sections stayed in the elastic area. During the seventeenth cycle, yielding was also observed at the other parts of the flange of the brace in brace-to-column connection, Fig. 13b. Development through the loading protocol, yielding spread along the brace OGrid-H, which has been shown in Fig. 13c-l, respectively. First yielding in the beam was observed during the twenty-eighth cycle at the top flange of the beam, Fig. $13 \mathrm{~m}$. Second yielding in the beam happened during the thirty-fifth cycle at the bottom flange of the beam, Fig. 13n. And eventually yielding in columns bases was observed during the fortieth and forty-first cycles, Fig. 13o, p. During the forty-sixth cycle, local buckling of the flange of the brace expanded. Local buckling of the brace OGrid-H has been shown in Fig. 14. Initiation of beam local buckling appeared during the forty-ninth cycle at the top flange of the beam, Fig. 15, and second beam local buckling occurred during the fifteenth cycle at the bottom flange of the beam, Fig. 15. It should be 


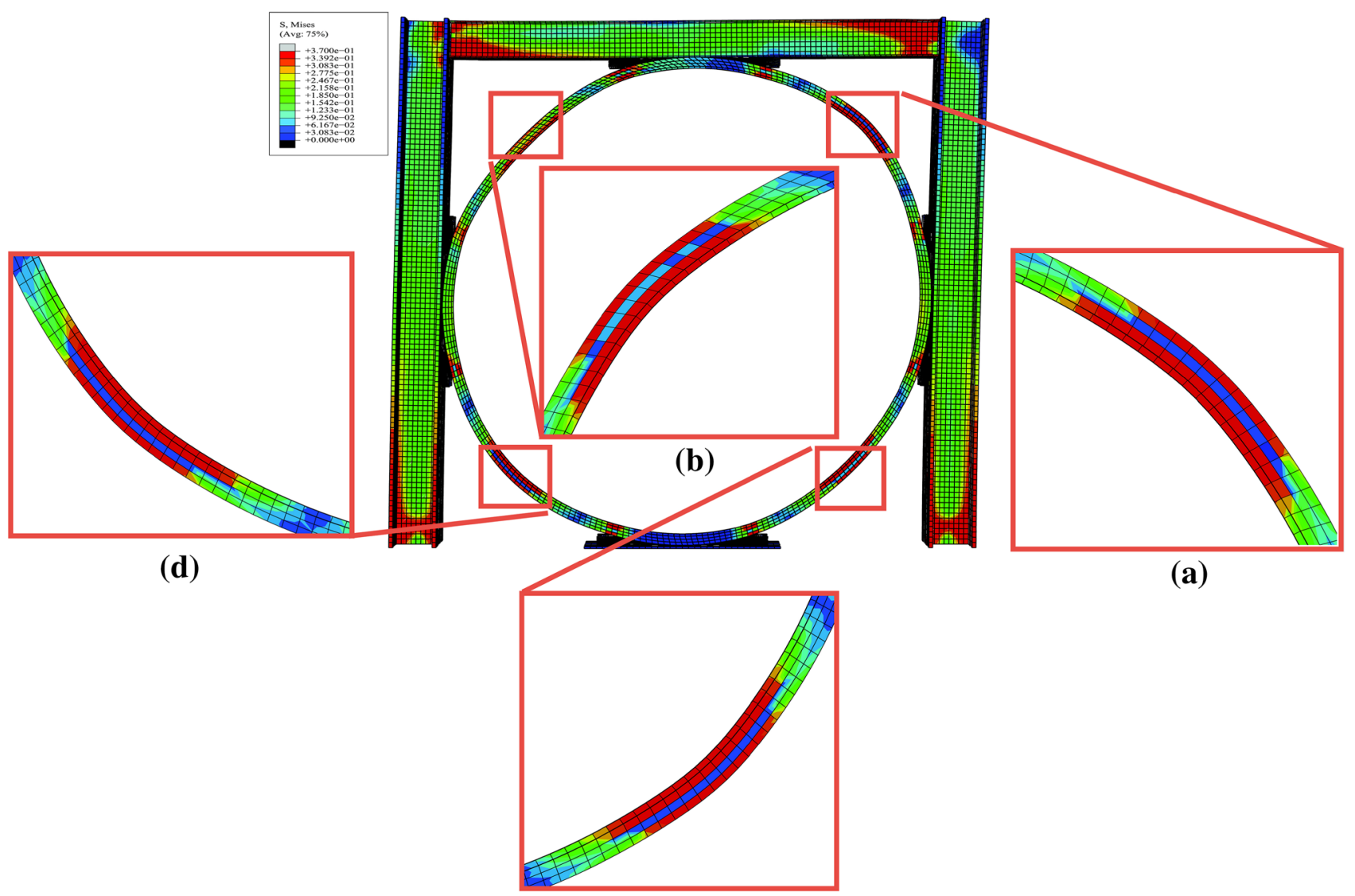

(c)

Fig. 14 Local buckling in the brace section of OGrid-H bracing system

mentioned that by buckling the brace OGrid- $\mathrm{H}$ and the beam, a considerable decadence in the hysteresis loops did not occur. Finally, the first local buckling in the columns was observed during the fifty-second cycle at the base of the column, Fig. 16, and second local buckling occurred at the base of another column during the fiftythird cycle, Fig. 16. Loading continued until $400 \mathrm{~mm}$ displacement (sixtieth cycle).

As shown in Figs. 13, 14, 15 and 16, plastic hinges initially formed in the brace, and then in beam and columns. Plastic hinges initially formed in brace-to-beam connections area of brace section and brace-to-column connections area of brace section. Number and arrangement of plastic hinges indicate appropriate nonlinearity capacity of the OGrid-H bracing system.

\subsection{Hysteresis curves}

Hysteresis results disclose some similarities also remarkable differences in the cyclic response of the OGH models. The following describes these behavioral characteristics. As seen in Fig. 17, the hysteresis curves are very fat and disclosed appropriate energy absorption to the structure. The hysteresis for all models are fairly symmetrical and all models represented ductile and stable behavior. All of the models were pushed until $400 \mathrm{~mm}$ displacement according to cyclic loading protocol Fig. 12. The maximum tension and compression forces for OGH-B1-C1-R1 were $1188.6 \mathrm{kN}$ and $1172.6 \mathrm{kN}$, respectively. The hysteresis curves of OGH-B1-C1-R1 until 5.5\% of the model's height is ascending and then become descending. Therefore, the fall of resistance has occurred in $5.5 \%$ of the model's height. The start points of degradation the hysteresis curves of models were different. Depending on different models, hysteresis curves of OGrid-H models until 5.5-7\% of model's height are ascending, and then are became descending. Therefore, the fall of resistance has occurred in $5.5-7 \%$ of model's height.

Table 4 shows the load capacity and the ratio of load capacity to weight of all OGH models and the maximum nonlinear displacements of all OGH models. Totally, load capacity and the stiffness of OGH models is appropriate. As seen in Table 4, OGH models have more displacement until destruction, which indicates desirable ductility of 


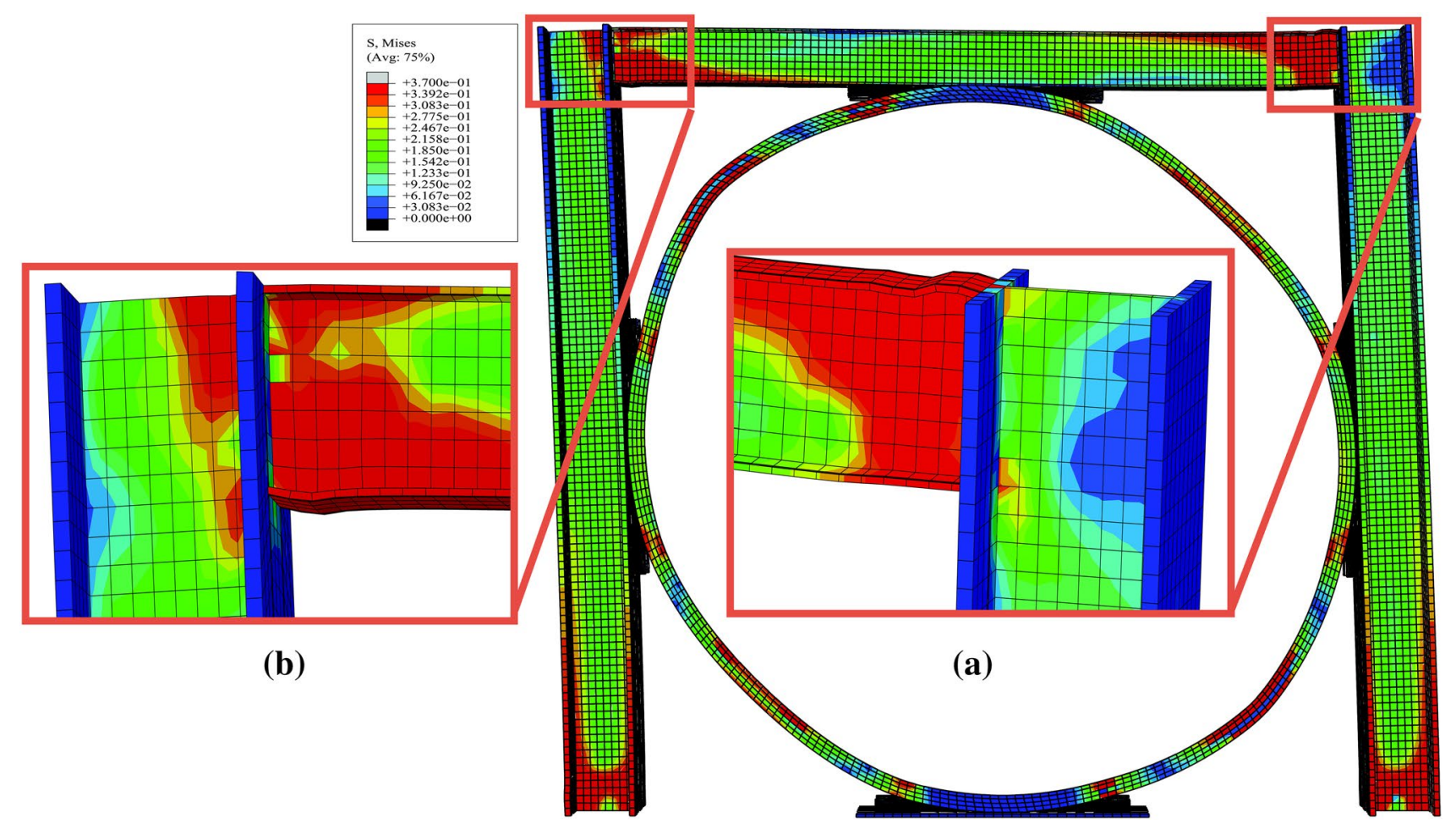

Fig. 15 Local buckling in the beam section of OGrid-H bracing system

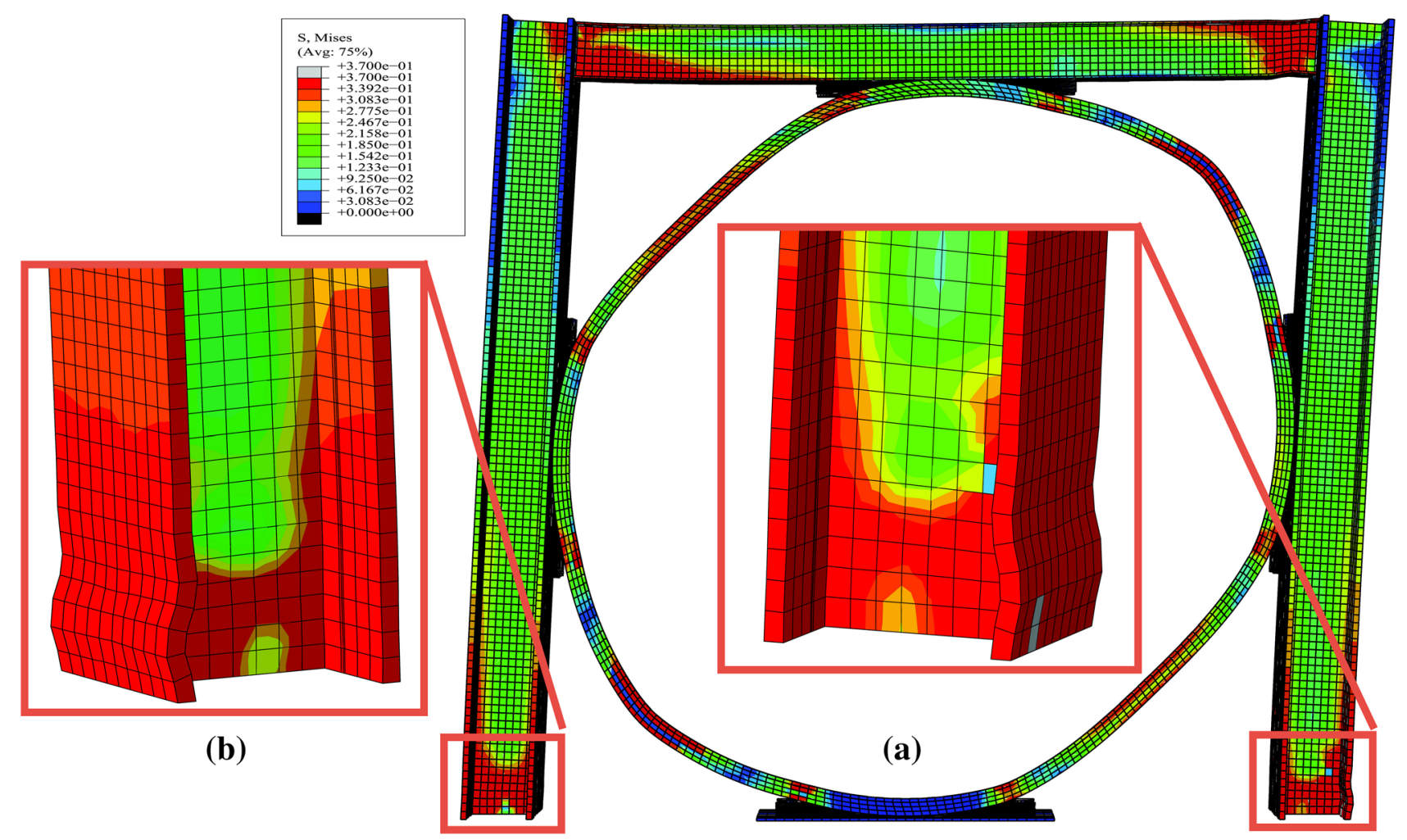

Fig. 16 Local buckling in the column section of OGrid-H bracing system 

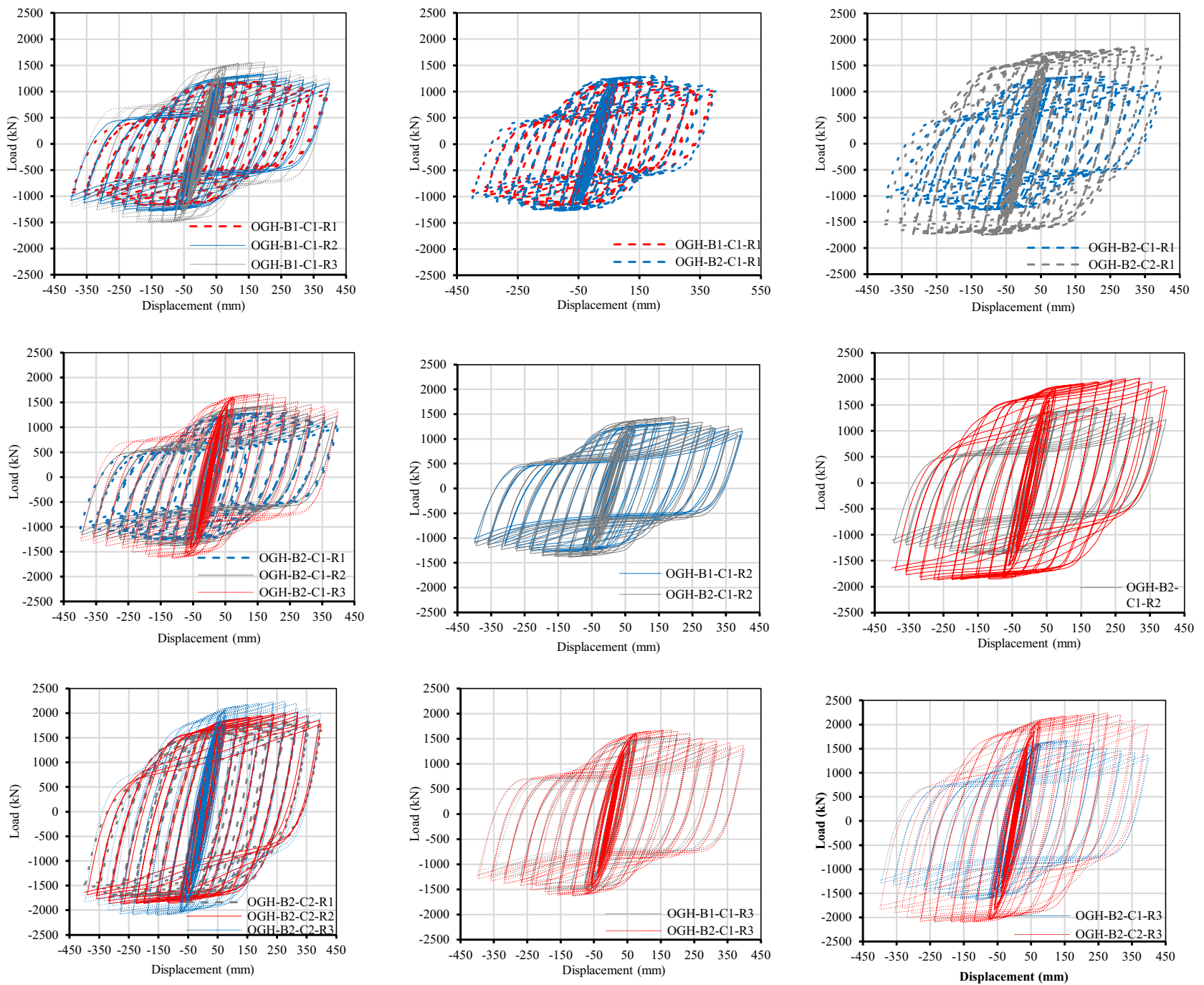

(a) Models with same beam and column sections and different brace section

(b) Models with same column and brace sections and different beam section

(c) Models with same beam and brace sections and different column section

Fig. 17 Hysteresis curves of OGH models

Table 4 Load capacity, ratio of load capacity to weight and maximum nonlinear displacement of OGH models

\begin{tabular}{|c|c|c|c|c|c|c|c|c|c|}
\hline Model & $\begin{array}{l}\text { OGH-B1- } \\
\text { C1-R1 }\end{array}$ & $\begin{array}{l}\text { OGH-B1- } \\
\text { C1-R2 }\end{array}$ & $\begin{array}{l}\text { OGH-B1- } \\
\text { C1-R3 }\end{array}$ & $\begin{array}{l}\text { OGH-B2- } \\
\text { C1-R1 }\end{array}$ & $\begin{array}{l}\mathrm{OGH}-\mathrm{B} 2- \\
\mathrm{C} 1-\mathrm{R} 2\end{array}$ & $\begin{array}{l}\text { OGH-B2- } \\
\text { C1-R3 }\end{array}$ & $\begin{array}{l}\text { OGH-B2- } \\
\text { C2-R1 }\end{array}$ & $\begin{array}{l}\text { OGH-B2- } \\
\text { C2-R2 }\end{array}$ & $\begin{array}{l}\mathrm{OGH}-\mathrm{B} 2- \\
\mathrm{C} 2-\mathrm{R} 3\end{array}$ \\
\hline $\begin{array}{l}\text { Load capac- } \\
\text { ity }(\mathrm{kN})\end{array}$ & 118.58 & 1340 & 1570 & 1299 & 1450 & 1670 & 1850 & 2020 & 2240 \\
\hline $\begin{array}{l}\text { Ratio of load } \\
\text { capacity to } \\
\text { weight }\end{array}$ & 51.4 & 57.2 & 66 & 52.6 & 58.2 & 66 & 52 & 57.7 & 63.6 \\
\hline $\begin{array}{l}\text { Maximum } \\
\text { nonlinear } \\
\text { displace- } \\
\text { ment } \\
(\mathrm{mm})\end{array}$ & 191.5 & 239.8 & 199.1 & 194.8 & 196.2 & 182.5 & 318.2 & 319.4 & 277.2 \\
\hline
\end{tabular}




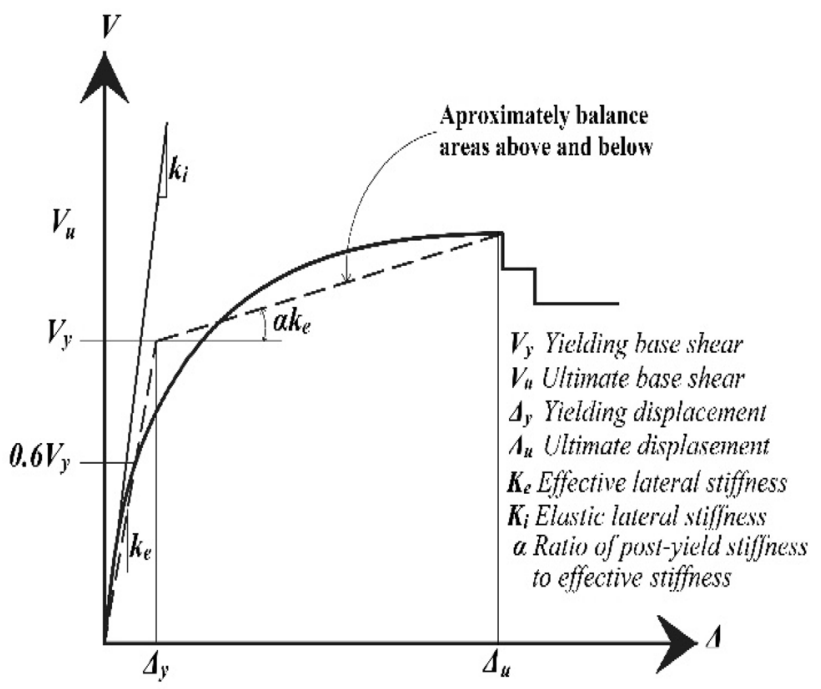

Fig. 18 Method of convert the base shear-displacement curve to ideal bilinear curve [44]

them. So, it can be concluded that OGH bracing models have desirable stiffness and ductility, and this new bracing system can get the benefits of CBF systems as a good stiffness and also the aims of MRF system such as flexibility and energy dissipating. As seen in Fig. 17 and Table 4, increasing the dimension of the brace in the models with the same beam section and the same column section is caused to $8-15 \%$ increasing the load capacity. Increasing the dimension of the beam in the models with the same column section and the same brace section is caused to $6-8 \%$ increasing the load capacity. And increasing the dimension of columns in the models with the same beam section and the same brace section is caused to $25-30 \%$ increasing the load capacity. Therefore, increasing the dimension of columns is the most effective changing and then increasing the dimension of the brace is effective, but increasing the dimension of the beam isn't so effective. Totally, by increasing the dimension of sections, the load capacity is increased, because the stiffness of sections is increased, so more loads transfers to the sections. Increasing the dimension of columns is the most effective changing on the section, because columns are the boundary elements and the most loads and couple of forces is applied to the columns.

The hysteresis push-force displacement curves which are the backbone curves of the hysteresis responses of the frames have been obtained according to FEMA-356 code [44]. According to FEMA-356 [44], the backbone curves has been drawn through the intersection of the first cycle curve for the ( $n$ )th deformation step with the second cycle curve of the $(n-1)$ th deformation step, for all $\mathrm{n}$ steps. These nonlinear force-displacement backbone

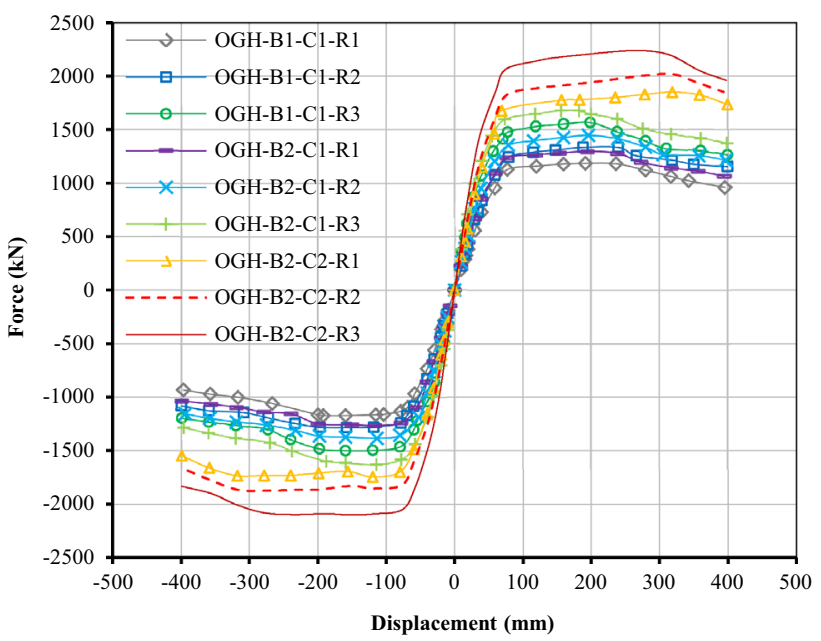

Fig. 19 Backbone curves of the hysteresis responses of OGH models

curves shall be replaced with an idealized bilinear curve to calculate the ductility factor $(\mu)$. So, according to FEMA356 [44], the idealized bilinear curve have been obtained, as shown in Fig. 18. Figure 19 shows the hysteresis pushforce displacement curves which are the backbone curves of the hysteresis responses of the frames that have been obtained according to FEMA-356 code [44]. From the idealized bilinear curve of OGH-B1-C1-R1, the maximum vertical displacement and corresponding vertical displacement of the system at the end of the tensile elastic limit are $191.5 \mathrm{~mm}$ and $29.6 \mathrm{~mm}$, respectively, based on two linearizations method of FEMA 356 [44]. Therefore, the ductility $(\mu)$ of the model can be calculated, such that:

$\mu=\frac{\Delta_{u}}{\Delta_{y}}=\frac{191.5}{29.6}=10.47$

Table 5 shows the ductility factor and the ratio of ductility factor to the weight of all OGH models. As seen in Table 5, OGH-B2-C2-R1 has the maximum ductility factor and $\mathrm{OGH}-\mathrm{B} 1-\mathrm{C} 1-\mathrm{R} 2$ has the maximum ratio of ductility factor to weight; which shows the ratio of yield to ultimate deformation of these models is more than other models.

\subsection{Vibration period and stiffness}

Figure 20 shows the force distribution of members. By having the vibration period of OGrid model and MRF model and by using Eq. 11, the stiffness of OGrid brace can be obtained. For this purpose, the vibration period of OGrid model and its corresponding MRF model have been obtained and then the stiffness of OGrid model and MRF model have been obtained through Eq. 11. By using 
Table 5 Ductility factor and ratio of ductility factor to weight of OGH models

\begin{tabular}{llllllllll}
\hline Model & $\begin{array}{l}\text { OGH-B1- } \\
\text { C1-R1 }\end{array}$ & $\begin{array}{l}\text { OGH-B1- } \\
\text { C1-R2 }\end{array}$ & $\begin{array}{l}\text { OGH-B1- } \\
\text { C1-R3 }\end{array}$ & $\begin{array}{l}\text { OGH-B2- } \\
\text { C1-R1 }\end{array}$ & $\begin{array}{l}\text { OGH-B2- } \\
\text { C1-R2 }\end{array}$ & $\begin{array}{l}\text { OGH-B2- } \\
\text { C1-R3 }\end{array}$ & $\begin{array}{l}\text { OGH-B2- } \\
\text { C2-R1 }\end{array}$ & $\begin{array}{l}\text { OGH-B2- } \\
\text { C2-R2 }\end{array}$ & $\begin{array}{l}\text { OGH-B2- } \\
\text { C2-R3 }\end{array}$ \\
\hline $\begin{array}{c}\text { Ductility } \\
\text { factor }(\mu)\end{array}$ & 6.47 & 8.03 & 6.79 & 6.55 & 6.6 & 6.24 & 10.86 & 10.81 \\
$\begin{array}{c}\text { Ductility } \\
\text { factor to } \\
\text { weight }\end{array}$ & 0.279 & 0.343 & 0.285 & 0.265 & 0.265 & 0.247 & 0.306 & 0.309 & 0.267 \\
\hline
\end{tabular}

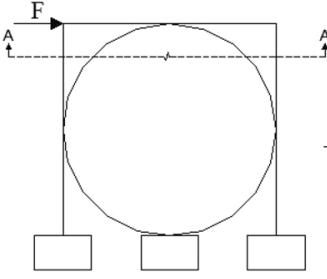

OGrid bracing frame

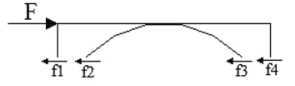

A-A section of OGrid bracing frame

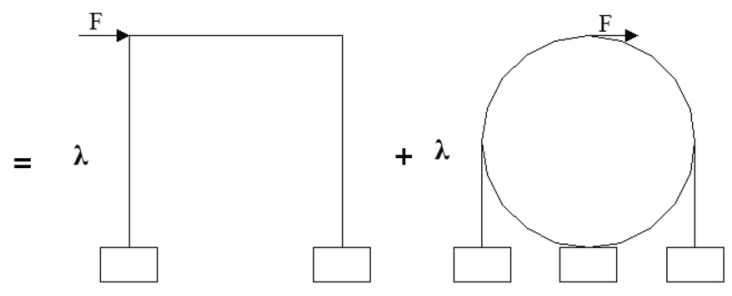

Fig. 20 Force distribution between frame members

Table 6 Vibration period and stiffness of models

\begin{tabular}{|c|c|c|c|c|c|c|c|c|c|}
\hline $\begin{array}{l}\text { Models } \\
\text { name }\end{array}$ & $\begin{array}{l}\text { OGH-B1- } \\
\text { C1-R1 }\end{array}$ & $\begin{array}{l}\text { OGH-B1- } \\
\mathrm{C} 1-\mathrm{R} 2\end{array}$ & $\begin{array}{l}\text { OGH-B1- } \\
\text { C1-R3 }\end{array}$ & $\begin{array}{l}\mathrm{OGH}-\mathrm{B} 2- \\
\mathrm{C} 1-\mathrm{R} 1\end{array}$ & $\begin{array}{l}\mathrm{OGH}-\mathrm{B} 2- \\
\mathrm{C} 1-\mathrm{R} 2\end{array}$ & $\begin{array}{l}\text { OGH-B2- } \\
\text { C1-R3 }\end{array}$ & $\begin{array}{l}\mathrm{OGH}-\mathrm{B} 2- \\
\mathrm{C} 2-\mathrm{R} 1\end{array}$ & $\begin{array}{l}\mathrm{OGH}-\mathrm{B} 2- \\
\mathrm{C} 2-\mathrm{R} 2\end{array}$ & $\begin{array}{l}\text { OGH-B2- } \\
\text { C2-R3 }\end{array}$ \\
\hline $\begin{array}{l}\text { Vibration } \\
\text { period (s) }\end{array}$ & 0.077 & 0.079 & 0.083 & 0.08 & 0.082 & 0.085 & 0.075 & 0.076 & 0.077 \\
\hline $\begin{array}{l}\text { Stiffness of } \\
\text { OGI model } \\
(\mathrm{kOGI})(\mathrm{kN} / \\
\mathrm{mm})\end{array}$ & 16.14 & 15.46 & 14.18 & 16.44 & 15.76 & 14.83 & 26.5 & 25.9 & 25.47 \\
\hline $\begin{array}{l}\text { Stiffness } \\
\text { of MRF } \\
\text { model } \\
(\mathrm{kMRF}) \\
(\mathrm{kN} / \mathrm{mm})\end{array}$ & 11.67 & 11.67 & 11.67 & 11.33 & 11.33 & 11.33 & 17.95 & 17.95 & 17.95 \\
\hline $\begin{array}{l}\text { Stiffness of } \\
\text { OGI brace } \\
\left(\mathrm{k}_{\mathrm{ROGI}}\right)(\mathrm{kN} / \\
\mathrm{mm})\end{array}$ & 4.47 & 3.79 & 2.5 & 5.11 & 4.43 & 3.5 & 8.54 & 7.99 & 7.51 \\
\hline
\end{tabular}

the stiffness of OGrid models and MRF models and Eqs. 9 and 10 , and by pass up the frame-to-brace interaction that shown as $\lambda$ in Fig. 20, the stiffness of OGrid braces are obtained.

Vibration period and stiffness of models have been presented in Table 6. As seen in Table 6, OGH-B2-C2-R1 and $\mathrm{OGH}-\mathrm{B} 2-\mathrm{C} 2-\mathrm{R} 2$ have appropriate behavior and have the most stiffness in all models. The stiffness is an effective factor against earthquake, but the ductility and the energy dissipation are important. The structures must have both appropriate stiffness and ductility, which the results show
OGH models can satisfy these aims and have appropriate stiffness and ductility.

$F=\left(f_{1}+f_{4}\right)+\left(f_{2}+f_{3}\right)=\left(k_{1}+k_{2}\right) \Delta$

$k_{O G H}=k_{M R F}+\left(k_{R O G H}\right)$

$T=2 \pi \sqrt{\frac{m}{k}} \Rightarrow K=\frac{4 \pi^{2} m}{T^{2}}$

$k_{O G H}=$ stiffness of OGrid-H models, $k_{M R F}=$ stiffness of MRF models, $k_{R O G H}=$ stiffness of OGrid-H braces. 


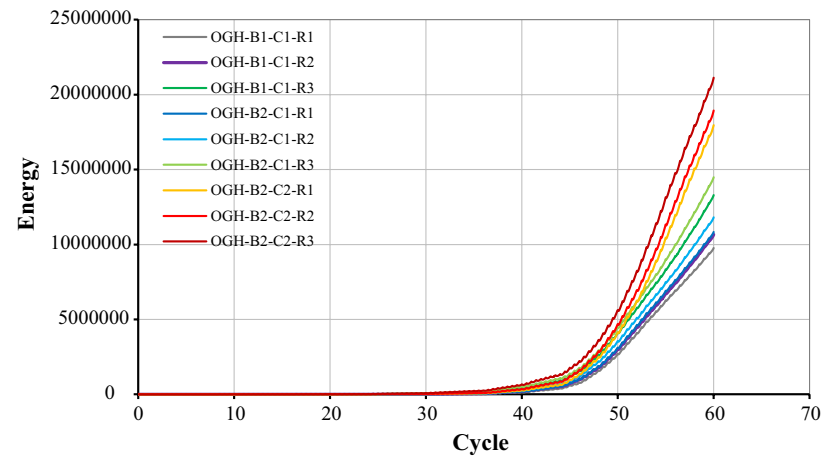

Fig. 21 Energy-loading cyclic plots of OGH models

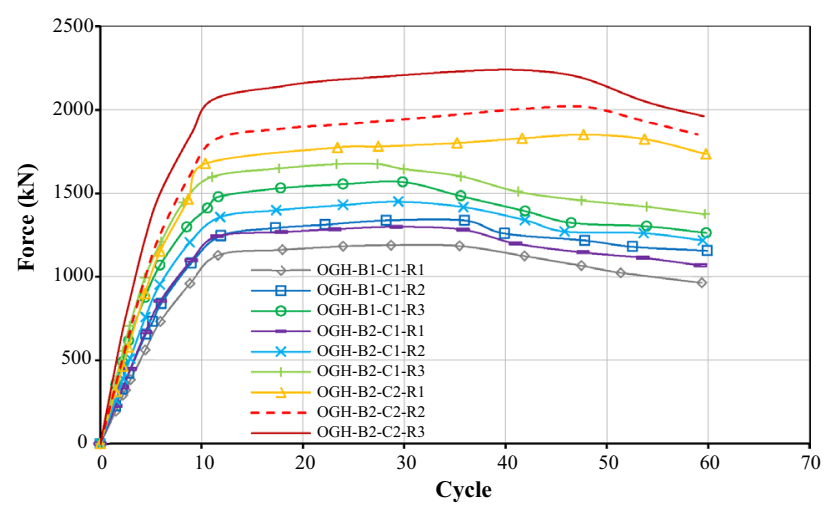

Fig. 22 Force-loading cyclic plots

\subsection{Energy absorption}

By energy dissipation specifications of a framed structure, its seismic performance can be obtained. By the hysteretic area which obtained from the analysis, the energy dissipation is illustrated, which is measured as the enclosed area by the load-displacement diagram. In Fig. 21 energyloading cycle plot of the OGrid-H bracing system has been shown. All models dissipated an appropriate amount of energies, which was the result of the nonlinear action of $\mathrm{OGH}$ bracing and a combination of bending deformation and tension yielding in the brace $\mathrm{OGH}$ and the creation of plastic hinges in the brace OGH. Figure 22 shows forceloading cycle plot of OGrid-H bracing systems.

In order to characterize the results, the analytical results have been shown in Table 7. It can be observed that the inelastic capacity of the OGH-B1-C1-R1 is 2.12 times of its elastic capacity. It can also be seen that energy in the last cycle is about 23.8 times of the one in the last cycle of the elastic range. In other words, energy absorption/force in the last cycle was 11.23 times of the one in the elastic range.

\subsection{Increase in load bearing}

In order to investigate the influence of new brace OGrid-H on load bearing of structures, 3 single-story and single-bay MRFs has been created with the same specification and load protocol of OGH models. In fact, in order to calculate the amount of increase in the load bearing of OGH models, and investigate the effect of brace OGrid-H on load bearing of structures, moment resisting frame (MRF) of each 9 models have been modeled, and the results have been shown in Fig. 23. Nomination of moment resisting frame models is similar to OGH models. Moment resisting frame models for simplification have been called MRF, then types of beam and column have been expressed respectively, for example, MRF-B1-C1. As it is seen in Fig. 23, the amount of increase in load bearing in $\mathrm{OGH}-\mathrm{B} 1-\mathrm{C} 1-\mathrm{R} 1$,

Table 7 Analytical results obtained from force-loading cycle plots and energy-loading cycle plots of OGH models

\begin{tabular}{|c|c|c|c|c|c|c|c|c|c|}
\hline $\begin{array}{l}\text { Models } \\
\text { name }\end{array}$ & $\begin{array}{l}\text { OGH-B1- } \\
\text { C1-R1 }\end{array}$ & $\begin{array}{l}\text { OGH-B1- } \\
\text { C1-R2 }\end{array}$ & $\begin{array}{l}\mathrm{OGH}-\mathrm{B} 1- \\
\mathrm{C} 1-\mathrm{R} 3\end{array}$ & $\begin{array}{l}\mathrm{OGH}-\mathrm{B} 2- \\
\mathrm{C} 1-\mathrm{R} 1\end{array}$ & $\begin{array}{l}\mathrm{OGH}-\mathrm{B} 2- \\
\mathrm{C} 1-\mathrm{R} 2\end{array}$ & $\begin{array}{l}\mathrm{OGH}-\mathrm{B} 2- \\
\mathrm{C} 1-\mathrm{R} 3\end{array}$ & $\begin{array}{l}\mathrm{OGH}-\mathrm{B} 2- \\
\mathrm{C} 2-\mathrm{R} 1\end{array}$ & $\begin{array}{l}\mathrm{OGH}-\mathrm{B} 2- \\
\mathrm{C} 2-\mathrm{R} 2\end{array}$ & $\begin{array}{l}\text { OGH-B2- } \\
\text { C2-R3 }\end{array}$ \\
\hline$E_{P-\max }(\mathrm{kJ})$ & 11.64 & 58.8 & 60.89 & 14.52 & 22.05 & 43.05 & 2193.6 & 2712.7 & 934.2 \\
\hline$E_{E-\max }(\mathrm{kJ})$ & 0.489 & 0.119 & 0.702 & 0.703 & 0.78 & 0.602 & 0.956 & 1.127 & 1.245 \\
\hline$P_{P-\max }(\mathrm{kN})$ & 1188.6 & 1336.6 & 1567.2 & 1299.2 & 1449.5 & 1674.6 & 1850.6 & 2017.3 & 2230.8 \\
\hline$P_{E-\max }(\mathrm{kN})$ & 559.5 & 656.15 & 874.5 & 667.8 & 758.7 & 993.9 & 899.4 & 1255.2 & 1500 \\
\hline$\beta_{E}=\frac{E_{P-\max }}{E_{E-\max }}$ & 23.8 & 493 & 86.7 & 20.66 & 28.27 & 71.51 & 2295.3 & 2406 & 750.3 \\
\hline$\beta_{P}=\frac{P_{P-\max }}{P_{E-\max }}$ & 2.12 & 2.04 & 1.79 & 1.94 & 1.91 & 1.68 & 2.06 & 1.61 & 1.49 \\
\hline \multicolumn{2}{|c|}{$\lambda=\frac{\beta_{E}=\frac{E_{P-\max }}{E_{E-\max }}}{\beta_{P}=\frac{P_{P-\max }}{\rho_{E-\max }}}$} & 241.7 & 48.4 & 10.65 & 14.8 & 42.56 & 1114.2 & 1494.4 & 503.5 \\
\hline
\end{tabular}

$E_{P-\max }$ Maximum plastic energy (Energy in the last nonlinear cycle); $E_{E-\text { max }}$ Maximum elastic energy (Energy in the first nonlinear cycle); $P_{P \text {-max }}$, Maximum plastic force (Force in the last nonlinear cycle); $P_{E-\text { max }}$, Maximum elastic force (Force in the first nonlinear cycle); $\beta_{E}$, The ratio of maximum plastic energy to maximum elastic energy; $\beta_{p_{1}}$ The ratio of maximum plastic force to maximum elastic force 


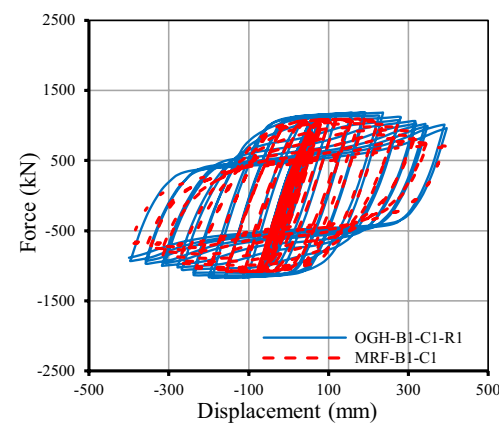

(a) OGH-B1-C1-R1 and MRF-B1-C1

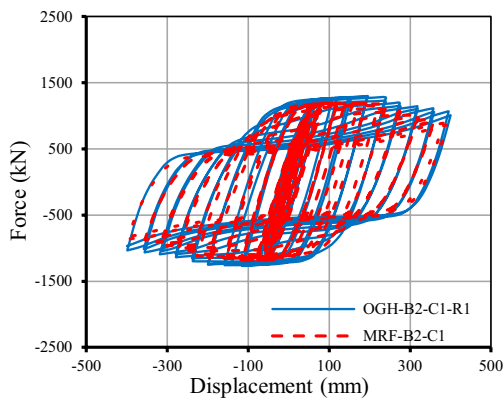

(d) OGH-B2-C1-R1 and MRF-B2-C1

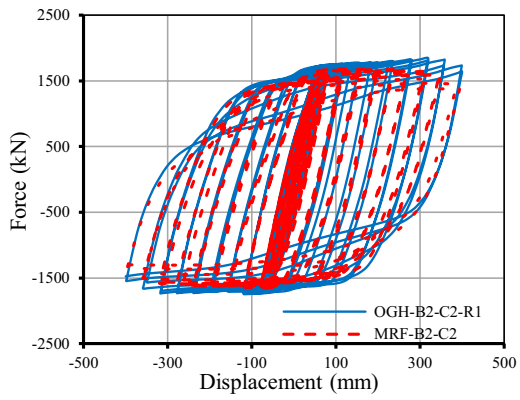

(g) OGH-B2-C2-R1 and MRF-B2-C2

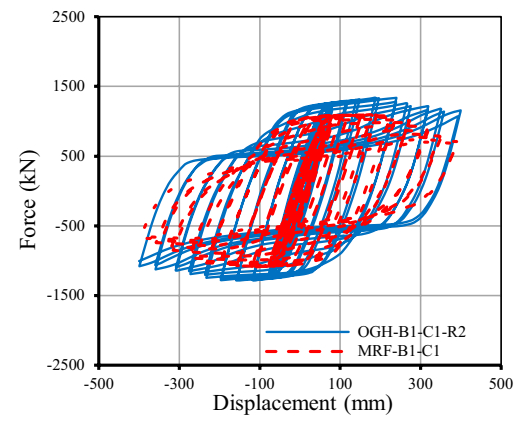

(b) OGH-B1-C1-R2 and MRF-B1-C1

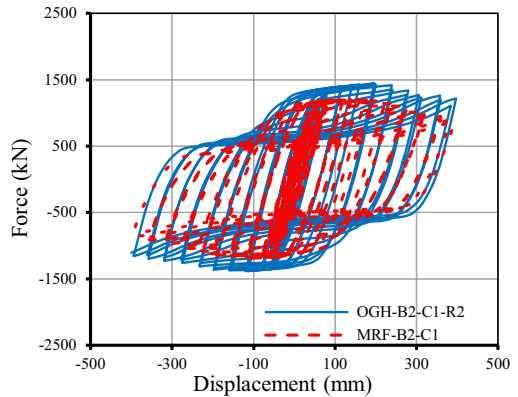

(e) OGH-B2-C1-R2 and MRF-B2-C1

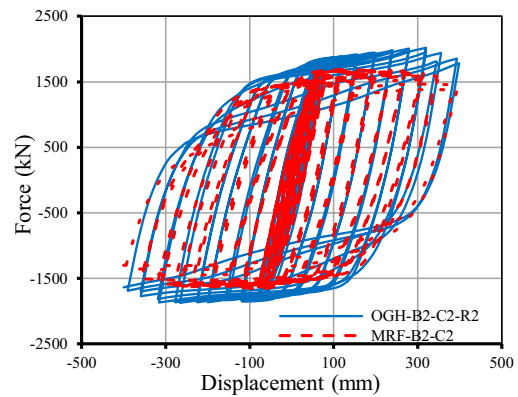

(h) OGH-B2-C2-R2 and MRF-B2-C2

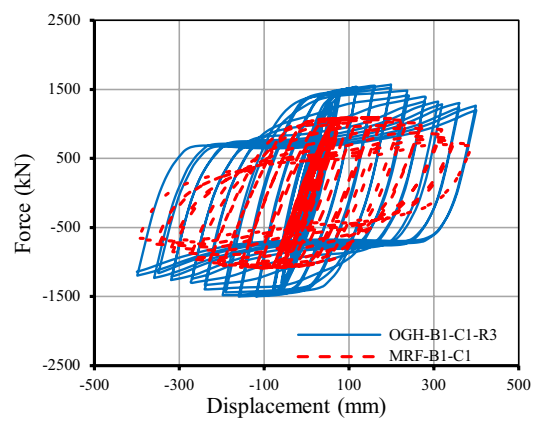

(c) OGH-B1-C1-R3 and MRF-B1-C1

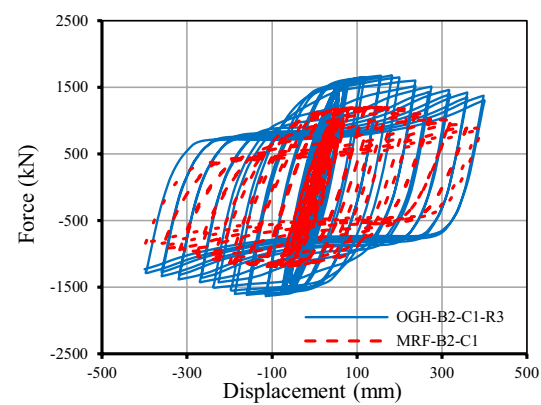

(f) OGH-B2-C1-R3 and MRF-B2-C1

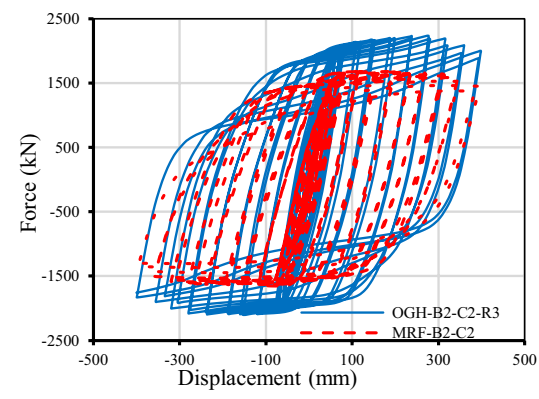

(i) OGH-B2-C2-R3 and MRF-B2-C2

Fig. 23 Comparison between hysteresis curves of OGH models and MRF models

OGH-B1-C1-R2,OGH-B1-C1-R3,OGH-B2-C1-R1,OGH-B2-C1-R2, OGH-B2-C1-R3, OGH-B2-C2-R1, OGH-B2-C2-R2 and OGH-B2-C2-R3 is $9 \%, 22 \%, 43 \%, 8 \%, 21 \%, 40 \%, 9 \%$, $19 \%$ and $32 \%$, respectively. The maximum amount is for $\mathrm{OGH}-\mathrm{B} 1-\mathrm{C} 1-\mathrm{R} 3$, and other OGH models have the appropriate increase in load bearing.

\section{Results conclusion and obtaining the optimum model}

The purpose of changing the sections of OGH models was for the maximum efficiency of the total system of beam, columns, and brace; to extract their effective and useful stiffness ratios. In this study, many results have been obtained for all OGH models. From the results of the previous section, some models in some parameters have the best behavior. So, because many results have been obtained and in order to obtain the optimal model from the 9 models which have been analyzed, a kind of statistical distribution has been used. Summary results of OGH models have been shown in Table 8. As seen in Table 8, the summary results of $\mathrm{OGH}$ models have been presented in percentage, so that for each parameter, $100 \%$ has been assigned to the model that has the best behavior. In the next step, in order to rate the models, the values of Table 8 have been ranking for each model. So that for each model, the number of parameters that have up to $95 \%, 85 \%, 75 \%, 65 \%$, and $50 \%$ have been 
Table 8 Summary results of OGH models in percentage

\begin{tabular}{|c|c|c|c|c|c|c|c|c|c|}
\hline Models name & $\begin{array}{l}\text { OGH- } \\
\text { B1-C1- } \\
\text { R1 }\end{array}$ & $\begin{array}{l}\mathrm{OGH}- \\
\mathrm{B} 1-\mathrm{C} 1- \\
\mathrm{R} 2\end{array}$ & $\begin{array}{l}\mathrm{OGH}- \\
\mathrm{B} 1-\mathrm{C} 1- \\
\mathrm{R} 3\end{array}$ & $\begin{array}{l}\mathrm{OGH}- \\
\mathrm{B} 2-\mathrm{C} 1- \\
\mathrm{R} 1\end{array}$ & $\begin{array}{l}\mathrm{OGH}- \\
\mathrm{B} 2-\mathrm{C} 1- \\
\mathrm{R} 2\end{array}$ & $\begin{array}{l}\mathrm{OGH}- \\
\mathrm{B} 2-\mathrm{C} 1- \\
\mathrm{R} 3\end{array}$ & $\begin{array}{l}\mathrm{OGH}- \\
\mathrm{B} 2-\mathrm{C} 2- \\
\mathrm{R} 1\end{array}$ & $\begin{array}{l}\mathrm{OGH}- \\
\mathrm{B} 2-\mathrm{C} 2- \\
\mathrm{R} 2\end{array}$ & $\begin{array}{l}\mathrm{OGH}- \\
\text { B2-C2- } \\
\text { R3 }\end{array}$ \\
\hline Maximum tolerable load & 53 & 60 & 70 & 58 & 65 & 74 & 83 & 90 & 100 \\
\hline Ratio of maximum tolerable load to weight & 78 & 86 & 99.7 & 80 & 88 & 100 & 79 & 87 & 96 \\
\hline Maximum nonlinear displacement & 60 & 75 & 62 & 61 & 61 & 57 & 99.6 & 100 & 87 \\
\hline Ductility factor $(\mu)$ & 56 & 64 & 72 & 56 & 71 & 55 & 100 & 89 & 86 \\
\hline Ratio of ductility factor to weight & 88 & 100 & 88 & 83 & 83 & 80 & 81 & 93 & 89 \\
\hline Vibration period & 91 & 93 & 98 & 94 & 96 & 100 & 88 & 89 & 91 \\
\hline Stiffness & 61 & 58 & 54 & 62 & 59 & 56 & 100 & 98 & 96 \\
\hline Energy absorption & 0.43 & 2.17 & 2.24 & 0.53 & 0.81 & 1.59 & 80.9 & 100 & 34.4 \\
\hline $\begin{array}{l}\text { Ratio of maximum plastic energy to maximum } \\
\text { elastic energy }\left(\beta_{E}\right)\end{array}$ & 0.98 & 20 & 4 & 0.86 & 5 & 3 & 95 & 100 & 31 \\
\hline $\begin{array}{l}\text { Ratio of maximum plastic force to maximum elastic } \\
\text { force }\left(\beta_{p}\right)\end{array}$ & 100 & 96 & 84 & 91 & 90 & 79 & 97 & 76 & 70 \\
\hline$\lambda=\frac{\beta_{E}}{\beta_{P}}$ & 0.75 & 16 & 3 & 0.71 & 5 & 3 & 74 & 100 & 34 \\
\hline $\begin{array}{l}\text { Increase in load bearing of OGH models in compar- } \\
\text { ison with similar MRF models (\%) }\end{array}$ & 21 & 51 & 100 & 19 & 49 & 93 & 21 & 44 & 74 \\
\hline
\end{tabular}

Table 9 Scoring of OGH models

\begin{tabular}{|c|c|c|c|c|c|c|c|c|c|}
\hline Models name & $\begin{array}{l}\mathrm{OGH}- \\
\mathrm{B} 1-\mathrm{C} 1- \\
\mathrm{R} 1\end{array}$ & $\begin{array}{l}\mathrm{OGH}- \\
\mathrm{B} 1-\mathrm{C} 1- \\
\mathrm{R} 2\end{array}$ & $\begin{array}{l}\mathrm{OGH}- \\
\mathrm{B} 1-\mathrm{C} 1- \\
\mathrm{R} 3\end{array}$ & $\begin{array}{l}\text { OGH- } \\
\text { B2-C1- } \\
\text { R1 }\end{array}$ & $\begin{array}{l}\mathrm{OGH}- \\
\mathrm{B} 2-\mathrm{C} 1- \\
\text { R2 }\end{array}$ & $\begin{array}{l}\mathrm{OGH}- \\
\mathrm{B} 2-\mathrm{C} 1- \\
\text { R3 }\end{array}$ & $\begin{array}{l}\mathrm{OGH}- \\
\mathrm{B} 2-\mathrm{C} 2- \\
\mathrm{R} 1\end{array}$ & $\begin{array}{l}\mathrm{OGH}- \\
\mathrm{B} 2-\mathrm{C} 2- \\
\mathrm{R} 2\end{array}$ & $\begin{array}{l}\mathrm{OGH}- \\
\mathrm{B} 2-\mathrm{C} 2- \\
\text { R3 }\end{array}$ \\
\hline Up to $95 \%$ & 1 & 4 & 4 & 2 & 2 & 2 & 6 & 7 & 4 \\
\hline Up to $90 \%$ & 2 & 4 & 4 & 3 & 3 & 4 & 7 & 9 & 5 \\
\hline Up to $85 \%$ & 4 & 5 & 5 & 3 & 4 & 4 & 7 & 11 & 8 \\
\hline Up to $75 \%$ & 5 & 6 & 6 & 5 & 5 & 6 & 11 & 12 & 8 \\
\hline Up to $65 \%$ & 5 & 6 & 8 & 5 & 7 & 7 & 12 & 12 & 10 \\
\hline Up to $50 \%$ & 9 & 10 & 10 & 9 & 10 & 10 & 12 & 12 & 10 \\
\hline
\end{tabular}

Table 10 Properties of the optimal OGH model

\begin{tabular}{lllll}
\hline Optimal model & $\frac{A_{\text {Brace }}}{A_{\text {Beam }}}$ & $\frac{A_{\text {Brace }}}{A_{\text {Column }}}$ & $\frac{I_{\text {Brace }}}{I_{\text {Beam }}}$ & $\frac{I_{\text {Brace }}}{I_{\text {Column }}}$ \\
\hline OGH-B2-C2-R2 & 0.337 & 0.064 & 0.084 & 0.015 \\
\hline
\end{tabular}

$A_{\text {Brace, }}$ Brace cross section; $A_{\text {Beam }}$, Beam cross section; $A_{\text {Column }}$ Column cross section; $I_{\text {Brace }}$ Brace moment of inertia; $I_{\text {Beam }}$, Beam moment of inertia; $I_{\text {Column }}$ Column moment of inertia

obtained from Table 8 , and results have been presented in Table 9.

As seen in Table 9, OGH-B2-C2-R2 has the best score in all models and then OGI-B2-C2-R1 has an appropriate score, and these models have the best behavior in all models. Therefore, OGI-B2-C2-R2 can be selected to the optimum model with the best section's dimension among 9 analyzed models. The ratios of cross section and the ratios of the moment of inertia in model OGI-B2-C2-R2 which has the optimal brace section, beam section, and column section, have been presented in Table 10. It should be noted that for the design procedure and related criteria of this new lateral bracing system, more studies should be done; so, these ratios can be so effective in the next stage of the research on this new lateral bracing system.

\section{Connections optimization}

In order to study on connections of the OGrid-H bracing system, $\mathrm{OGH}$ model which has the maximum ratio of load capacity to weight has been selected, and some changes have been exerted in connections of this model. In OGH models, $\mathrm{OGH}-\mathrm{B} 1-\mathrm{C} 1-\mathrm{R} 3$ has the maximum ratio of load capacity to weight, so each change in connections has been separately exerted on OGH-B1-C1-R3 model. The model has been subjected to pushover displacement, and pushover curves have been obtained. The purpose of this analysis is to evaluate the effect of these changes in connections behavior and to obtain effective changes in OGrid-H connections. 


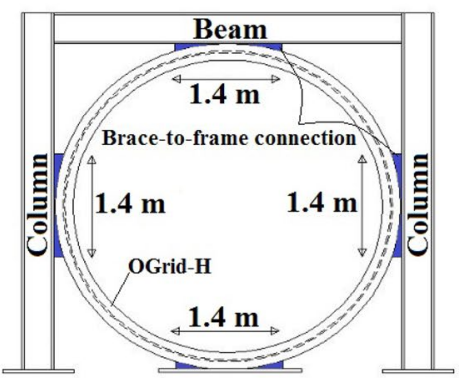

(a) base model

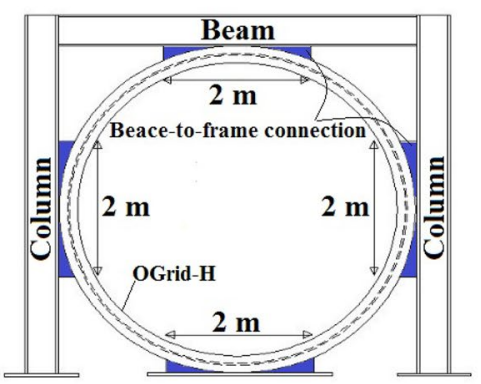

(b) changed model

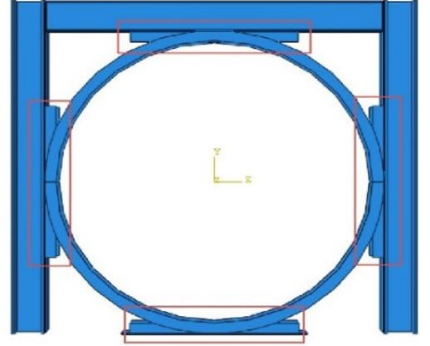

(c) schematic view in Abaqus

Fig. 24 Increasing the length of brace-to-frame connection plates

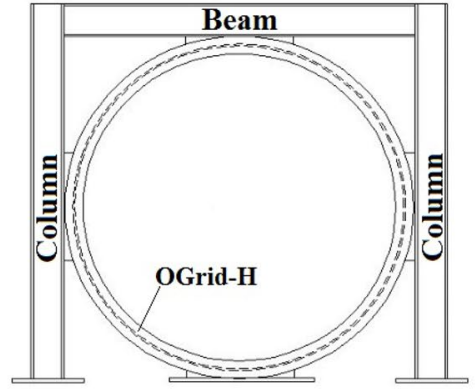

(a) base model

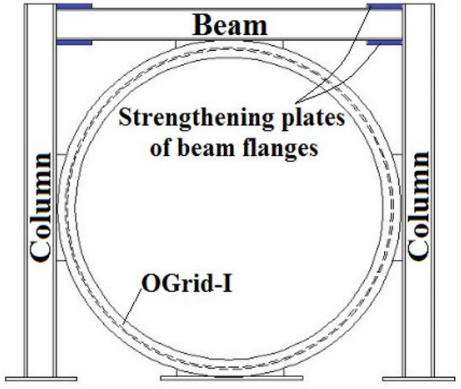

(b) changed model

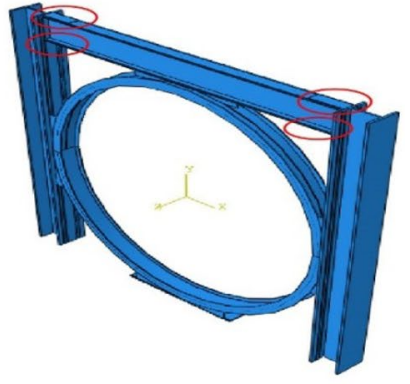

(c) schematic view in Abaqus

Fig. 25 Adding the strengthening plates in beam flanges in beam-to-column connections areas

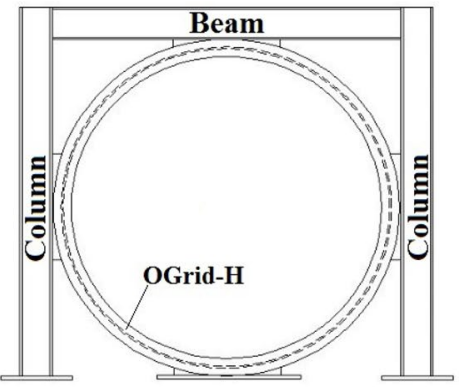

(a) base model

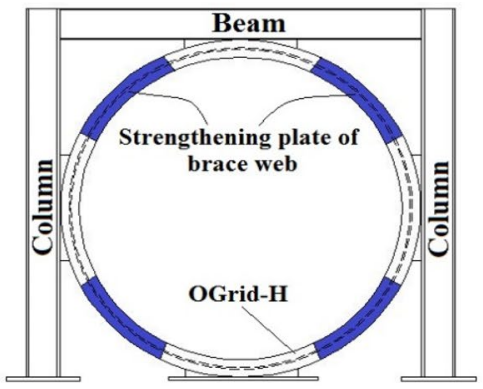

(b) changed model

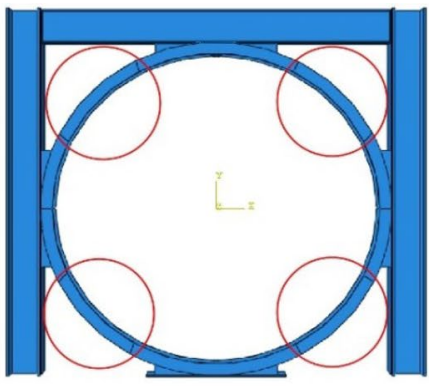

(c) schematic view in Abaqus

Fig. 26 Adding the strengthening plates in brace web in the areas that plastic hinges is formed

Exerted changes and the results have been separately expressed as follow. Figures 24, 25, 26, 27 and 28 show the changes in connections. Figure 24 shows the first change exerted in connections, which is increasing the length of brace-to-frame connection plates. Figure 25 shows the second change which is adding the strengthening plates in the flanges of the beam in beam-to-column connections areas. The third change has been shown in Fig. 26 is adding the strengthening plates in the web of the brace in the area that plastic hinges are formed. The fourth change is adding the continuity plates in beam-to-column connections, as shown in Fig. 27. And the fifth change is adding the stiffener plates in brace-to-frame connections areas, as shown in Fig. 28. Pushover curves of analysis have been shown in Fig. 29.

As it is seen in Fig. 29, increasing the length of brace-toframe connection plates is the most effective change, and then adding the strengthening plates in the web of the brace in the areas that plastic hinges are formed, and adding the strengthening plates in the flanges of the beam in 


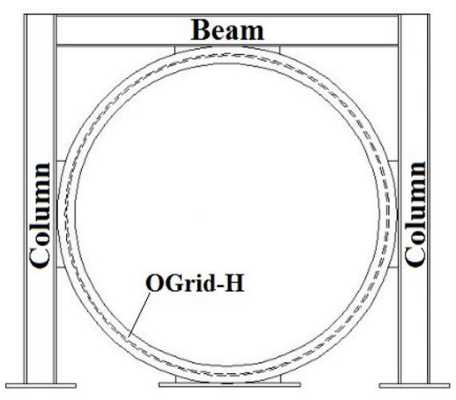

(a) base model

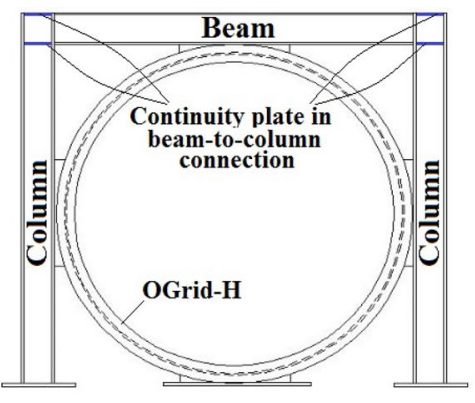

(b) changed model

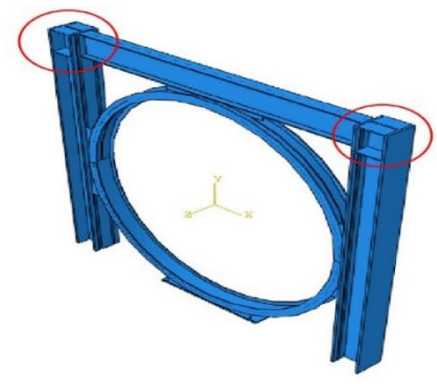

(c) schematic view in Abaqus

Fig. 27 Adding the continuity plates in beam-to-column connections

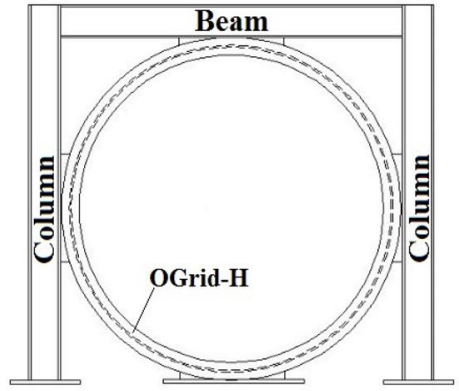

(a) base model

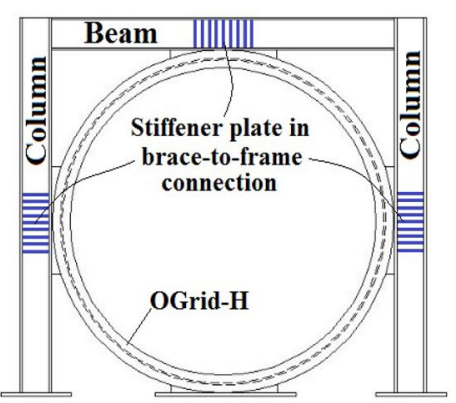

(b) changed model

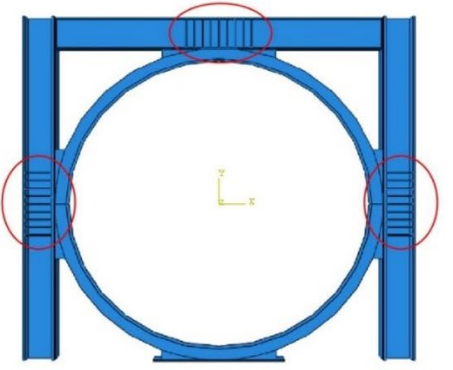

(c) schematic view in Abaqus

Fig. 28 Adding the stiffener plates in brace-to-frame connections areas

Fig. 29 Pushover curves of each changed models

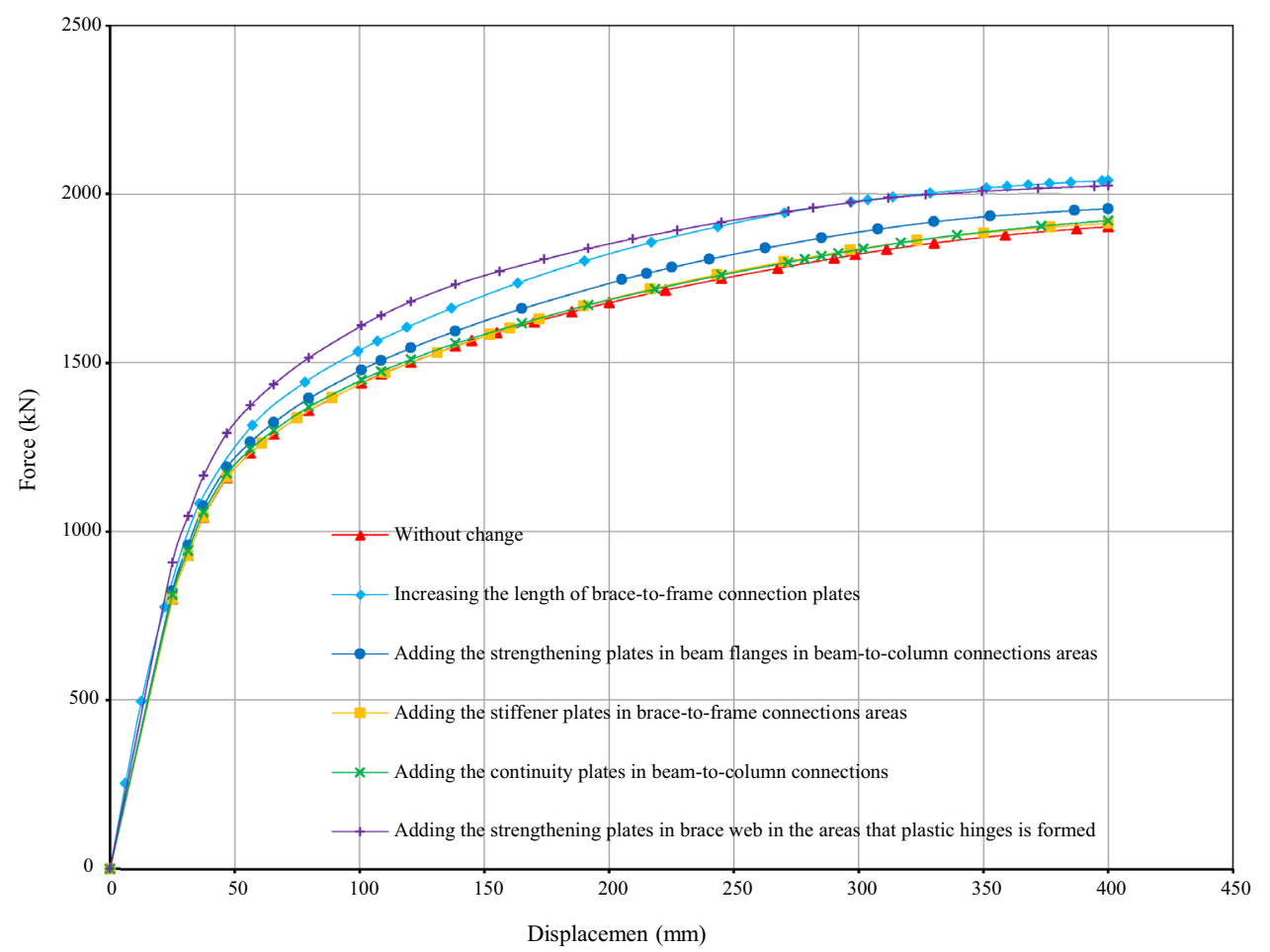

SN Applied Sciences 


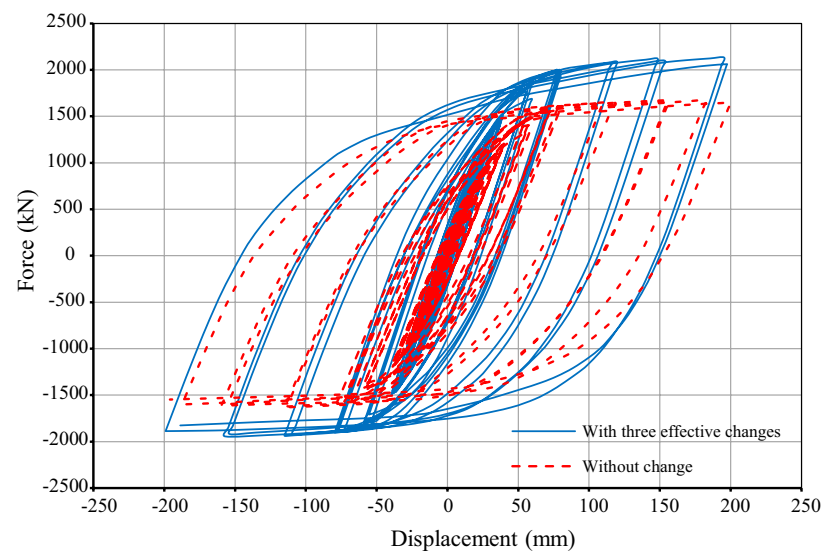

Fig. 30 Comparison between hysteresis curves of without change model with three effective changes

beam-to-column connections areas were effective. Therefore, these three changes have been simultaneously exerted on OGH-B1-C1-R3 and have been subjected to cyclic loading protocol (same to Fig. 12). Comparison between hysteresis curves of the model without any changes and the model with three effective changes have been shown in Fig. 30. As it is seen in Fig. 30, changes in connections has a desirable effect on load bearing of OGrid-H and has been caused to increase load bearing as the amount of $22.88 \%$. This analysis is the first analysis which performed on connections of new OGrid-H bracing frame, and in the future, more analysis is needed to investigate the behavior of this new bracing system.

\section{Conclusion}

The goal of this paper was to introduce new bracing frame with circular braces called OGrid- $\mathrm{H}$, and investigate the behavior of new OGrid-H bracing system with different sections and connections, and determine the optimal sections and connections. In order to investigate the OGrid-H members, 9 single story frames with brace OGrid-H have been analyzed and studied with ABAQUS finite element software under cyclic loading. The numerical study has been evaluated the hysteretic characteristics of new OGrid-H bracing system with different sections and connections under repeated cyclic loading. The stiffness, displacement, force distribution pattern, ductility, and energy absorption has been determined. All OGrid-H models indicated ductile and stable behavior and the hysteresis curves of models were fairly symmetrical. The intensive bending deformation occurred for the brace section, and the beam and column members did not endure intensive deformation. OGrid-H models dissipated a significant amount of cumulative energies, which maximum energy absorption was $2713 \mathrm{~kJ}$. OGrid$\mathrm{H}$ models showed appropriate load capacity and also ductile behavior, which the maximum load capacity and the maximum ductility factor was $2231 \mathrm{kN}$ and 10.86, respectively. Results showed that increasing the dimension of columns is the most effective changing and then increasing the dimension of the brace is effective, but increasing the dimension of the beam isn't so effective. The analytical results and comparison between results of these 9 models lead to obtaining the model which has higher performance than the others, and the ratios of cross section and the ratios of the moment of inertia in this model which has the optimal brace section, beam section, and column section, has been obtained. In order to investigate the OGrid-H connections, 5 changes have been applied to connections. Increasing the length of brace-to-frame connection plates was the most effective change, and then adding the strengthening plates in the web of the brace in the areas that plastic hinges are formed, and adding the strengthening plates in the flanges of the beam in beam-to-column connections areas were effective. The results showed that these changes had the greatest influence, which caused to increase load bearing as the amount of $22.88 \%$.

\section{Compliance with ethical standards}

Conflict of interest The authors declare that they have no conflict of interest.

Ethical approval This chapter does not contain any studies with human participants or animals performed by any of the authors.

\section{References}

1. Shariati A, Shariati M, Sulong NR, Suhatril M, Khanouki MA, Mahoutian M (2014) Experimental assessment of angle shear connectors under monotonic and fully reversed cyclic loading in high strength concrete. Constr Build Mater 52:276-283. https ://doi.org/10.1016/j.conbuildmat.2013.11.036

2. Shariati M, Shariati A, Sulong NR, Suhatril M, Khanouki MA (2014) Fatigue energy dissipation and failure analysis of angle shear connectors embedded in high strength concrete. Eng Fail Anal 41:124-134. https://doi.org/10.1016/j.engfailanal.2014.02.017

3. Kachooee A, Kafi MA (2018) A suggested method for improving post buckling behavior of concentric braces based on experimental and numerical studies. Structures 14:333-347. https:// doi.org/10.1016/j.istruc.2018.04.003

4. Kachooee A, Kafi MA, Gerami M (2018) The effect of local fuse on behavior of concentrically braced frame by a numerical study. Civ Eng J 4(3):655-667. https://doi.org/10.28991/cej-0309123

5. Shafieifar M, Farzad M, Azizinamini A (2017) Alternative ABC connection utilizing UHPC. 17-03398

6. Shafieifar M, Farzad M, Azizinamini A (2017) Experimental and numerical study on mechanical properties of Ultra High 
Performance Concrete (UHPC). Constr Build Mater 156:402-411. https://doi.org/10.1016/j.conbuildmat.2017.08.170

7. Farzad M, Mohammadi A, Shafieifar M, Pham H, Azizinamini A (2017) Development of innovative bridge systems utilizing steel-concrete-steel sandwich. In: System. proceedings, 96th annual meeting, transportation research board, Washington DC, United States, No. 17-02229

8. Marshall JD, Charney FA (2010) A hybrid passive control device for steel structures, I: development and analysis. J Constr Steel Res 66(10):1278-1286. https://doi.org/10.1016/j.jcsr.2010.04.005

9. Marshall JD, Charney FA (2010) A hybrid passive control device for steel structures, II: physical testing. J Constr Steel Res 66(10):1287-1294. https://doi.org/10.1016/j.jcsr.2010.04.002

10. Mansouri I, Safa M, Ibrahim Z, Kisi O, Tahir MM, Baharom S, Azimi $M$ (2016) Strength prediction of rotary brace damper using MLR and MARS. Struct Eng Mech 60(3):471-488. https://doi. org/10.12989/sem.2016.60.3.471

11. Boadi-Danquah E, MacLachlan D, Fadden M (2018) Cyclic performance of a lightweight rapidly constructible and reconfigurable modular steel floor diaphragm. In: Key engineering materials, vol 763. Trans Tech Publications, pp 541-48. https://doi. org/10.4028/www.scientific.net/KEM.763.541

12. Kodur V, Yahyai M, Rezaeian A, Eslami M, Poormohamadi A (2017) Residual mechanical properties of high strength steel bolts subjected to heating-cooling cycle. J Constr Steel Res 131:122-131. https://doi.org/10.1016/j.jcsr.2017.01.007

13. Eslami M, Namba H (2016) Elasto-plastic behavior of composite beam connected to RHS column, experimental test results. Int J Steel Struct 16(3):901-912. https://doi.org/10.1007/s1329 6-015-0067-3

14. Eslami M, Namba H (2016) Mechanism of elasto-plastic behavior of composite beam connected to RHS column. Int J Steel Struct 16(3):913-933. https://doi.org/10.1007/s1329 6-015-0068-2

15. Eslami M, Namba H (2016) Rotation capacity of composite beam connected to RHS column, experimental test results. Steel Compos Struct 22(1):141-159. https://doi.org/10.12989 /scs.2016.22.1.141

16. Gélinas A, Tremblay R, Davaran A (2012) Seismic behavior of steel HSS X-bracing of the conventional construction category. In: Structures congress, pp. 1649-1660. https://ascel ibrary.org/doi/abs/10.1061/9780784412367.146

17. Giannuzzi D, Ballarini R, Huckelbridge A Jr, Pollino M, Valente M (2013) Braced ductile shear panel: new seismic-resistant framing system. J Struct Eng 140(2):04013050. https://doi. org/10.1061/(ASCE)ST.1943-541X.0000814

18. Kang JD, Tagawa H (2013) Seismic performance of steel structures with seesaw energy dissipation system using fluid viscous dampers. J Eng Struct 30(56):431-442. https://doi. org/10.1016/j.engstruct.2013.05.015

19. Bandehzadeh M, Ashtari P (2015) T-Resisting Frame concept: headway towards seismic performance improvement of steel frames. J Constr Steel Res 104:193-205. https://doi. org/10.1016/j.jcsr.2014.10.018

20. Dimakogianni D, Dougka G, Vayas I (2015) Seismic behavior of frames with innovative energy dissipation systems (FUSEIS1-2). J Eng Struct 90:83-95. https://doi.org/10.1016/j. engstruct.2015.01.054

21. Mahjoubi S, Maleki S (2016) Seismic performance evaluation and design of steel structures equipped with dual-pipe dampers. J Constr Steel Res 122:25-39. https://doi.org/10.1016/j. jcsr.2016.01.023

22. Guo YL, Zhang BH, Zhu BL, Zhou P, Zhang YH, Tong JZ (2017) Theoretical and experimental studies of battened bucklingrestrained braces. J Eng Struct 136:312-328. https://doi. org/10.1016/j.engstruct.2017.01.034
23. Shen J, Seker O, Akbas B, Seker P, Momenzadeh S, Faytarouni $M$ (2017) Seismic performance of concentrically braced frames with and without brace buckling. Eng Struct 141:461-481. https://doi.org/10.1016/j.engstruct.2017.03.043

24. Momenzadeh S, Seker O, Faytarouni M, Shen J (2017) Seismic performance of all-steel buckling-controlled braces with various cross-sections. J Constr Steel Res 139:44-61. https://doi. org/10.1016/j.jcsr.2017.09.003

25. Serror MH, Abdelmoneam MN (2016) Seismic performance evaluation of Egyptian code designed steel moment resisting frames. HBRC J. https://doi.org/10.1016/j.hbrcj.2016.01.005

26. Güneyisi EM, Gültekin A (2017) Nonlinear behaviour of midrise steel buildings with gate braced frames. Open Civ Eng J. https://doi.org/10.2174/1874149501711010475

27. Zahrai SM, Cheraghi A (2017) Improving cyclic behavior of multi-level pipe damper using infill or slit diaphragm inside inner pipe. Struct Eng Mech 64(2):195-204

28. Zahrai SM, Cheraghi A (2017) Reducing seismic vibrations of typical steel buildings using new multi-level yielding pipe damper. Int J Steel Struct 17(3):983-998. https://doi. org/10.1007/s13296-017-9010-0

29. Cheraghi A, Zahrai SM (2017) Cyclic testing of multilevel pipe in pipe damper. J Earthq Eng. https://doi.org/10.1080/13632 469.2017.1387191

30. Cheraghi A, Zahrai SM (2016) Innovative multi-level control with concentric pipes along brace to reduce seismic response of steel frames. J Constr Steel Res 127:120-135. https://doi. org/10.1016/j.jcsr.2016.07.024

31. EbadiJamkhaneh $M$, HomaioonEbrahimi $A$, ShokriAmiri $M$ (2018) Seismic performance of steel-braced frames with an allsteel buckling restrained brace. Pract Period Struct Des Constr 23(3):04018016. https://doi.org/10.1061/(ASCE)SC.19435576.0000381

32. Murthy ANCK (2005) Application of visco-hyperelastic devices in structural response control. M.Sc. Thesis, Civil Engineering Department, Blacksburg Polytechnic Institute, Virginia Polytechnic Institute and State University. https://vtechworks.lib.vt.edu/ handle/10919/32910

33. Bazzaz M, Kheyroddin A, Kafi MA, Andalib Z (2012) Evaluation of the seismic performance of off-centre bracing system with ductile element in steel frames. Steel Compos Struct 12(5): 445-464

34. Bazzaz M, Kafi MA, Kheyroddin A, Andalib Z, Esmaeili H (2014) Evaluating the seismic performance of off-centre bracing system with circular element in optimum place. Int J Steel Struct 14(2):293-304. https://doi.org/10.1007/s13296-014-2009-x

35. Andalib Z, Kafi MA, Kheyroddin A, Bazzaz M (2014) Experimental investigation of the ductility and performance of steel rings constructed from plates. J Constr Steel Res 103:77-88

36. Bazzaz M, Andalib Z, Kafi MA, Kheyroddin A (2015) Evaluating the performance of OBS-CO in steel frames under monotonic load. J Earthq Struct 8(3):697-710

37. Bazzaz M, Andalib Z, Kheyroddin A, Kafi MA (2015) Numerical comparison of the seismic performance of steel rings in off-centre bracing system and diagonal bracing system. J Steel Compos Struct 19(4):917-937

38. Andalib Z, Kafi MA, Kheyroddin A, Bazzaz M, Momenzadeh S (2018) Numerical evaluation of ductility and energy absorption of steel rings constructed from plates. J Eng Struct 169:94-106. https://doi.org/10.1016/j.engstruct.2018.05.034

39. Boostani M, Rezaifar O, Gholhaki M (2018) Introduction and seismic performance investigation of the proposed lateral bracing system called OGrid. Arch Civ Mech Eng 18(4):1024-1041. https ://doi.org/10.1016/j.acme.2018.02.003

40. ASTM (American Society of Testing and Materials) (2007) Standard test methods for cyclic (reversed) load test for shear 
resistance of vertical elements of the lateral force resisting systems for buildings. ASTM E2126-07a

41. ASCE (American Society of Civil Engineers ASCE/SEI) (2011) Minimum design loads for buildings and other structures. ASCE 7-10

42. AISC (American Institute of Steel Construction ANSI/AISC) (2010) Specification for structural steel buildings. AISC 360-10

43. ATC (Applied Technology Council) (1992) Guidelines for cyclic seismic testing of components of steel structures. ATC-24. Redwood City, CA
44. FEMA (Federal Emergency Management Agency) (2000) Commentary for the seismic rehabilitation of buildings. FEMA-356. Washington, DC

Publisher's Note Springer Nature remains neutral with regard to jurisdictional claims in published maps and institutional affiliations. 